\title{
Regulation and clinical significance of O-GIcNAc transferase in cancer
}

\author{
Xinling Zhang ${ }^{1}$, Yuchao Gu ${ }^{2}$, Wengong $\mathbf{Y u}^{2}$ and Hui Liang ${ }^{1}$ \\ ${ }^{1}$ The Institute of Human Nutrition, Medical College of Qingdao University, Qingdao 266021, China \\ ${ }^{2}$ Key Laboratory of Marine Drugs, Chinese Ministry of Education, Key Laboratory of Glycoscience and Glycotechnology of \\ Shandong Province; School of Medicine and Pharmacy, Ocean University of China, Qingdao 266003, China \\ Correspondence to: Hui Liang, email: ajgqdfy@163.com \\ Xinling Zhang, email: ruoxi_67@163.com
}

Keywords: OGT; O-GlcNAcylation; expression; protein stability; activity

Received: June 14, 2017 Accepted: November 03, $2017 \quad$ Published: January 02, 2018

Copyright: Zhang et al. This is an open-access article distributed under the terms of the Creative Commons Attribution License 3.0 (CC BY 3.0), which permits unrestricted use, distribution, and reproduction in any medium, provided the original author and source are credited.

\begin{abstract}
O-GIcNAC Transferase (OGT) resides in both cytosolic and nuclear compartments and catalyzes O-GIcNAcylation of myriad proteins. Numerous excellent reviews concerning roles of OGT in organismal and cellular physiology have exist, and aberrant OGT and protein O-GIcNAcylation have been implicated in progression and metastasis of different cancer types. Thus, understanding the regulation mechanisms of OGT and 0-GIcNAcylation in tumor cells and their difference compared to non-tumor cells may elucidate new mechanisms related to tumor generation and development, could provide a new marker to diagnosis and prognosis in patients with cancer and indicate a new target to cancer chemotherapy. While it has become evident that OGT plays critical roles in cancers, it remains unclear how they are deregulated. This review provides an overview of our current knowledge about the known/potential regulation of OGT, and also discusses the inhibition of OGT as a potential novel therapeutic target for cancer treatment.
\end{abstract}

\section{INTRODUCTION}

O-GlcNAcylation is the covalent connection of O-GlcNAc sugars to serine or threonine residues of nuclear and cytoplasmic proteins in metazoans [1-5]. Like phosphorylation, O-GlcNAcylation is an inducible, reversible, and dynamic posttranslational modification. To date, more than 4,000 O-GlcNAcylated proteins have been detected [6] and these proteins have been involved in nearly every aspect of the cellular physiology [7], including gene expression [8-11], metabolism [12-16], cellular stress responses $[17,18]$, signal transduction $[19,20]$, and proteostasis [21-24] in response to nutrient availability [7,25]. Given the myriad functions concerned with O-GlcNAcylation, it is exceedingly reasonable that this posttranslational modification plays a fundamental role in the etiology of tumors $[6,14,26-28]$. Indeed, O-GlcNAcylation is deregulated in many cancer types, including breast $[29,30]$, pancreatic [31], prostate [32, 33], colorectal [34, 35], lung [34], liver [36], gastric $[37,38]$, laryngeal [39], bladder [40], endometrial [41], esophageal squamous cell carcinoma [42], and nonsolid cancers such as chronic lymphocytic leukemia [43], and contributes to cancer cell metabolic reprogramming, cell proliferation, survival, angiogenesis, invasion, metastasis and cancer cell epigenetics [14, 44].

Unlike phosphorylation, which is orchestrated by hundreds of phosphatases and kinases, O-GlcNAc cycling is regulated by a unique pair of highly conserved enzymes that add and hydrolyze O-GlcNAc moieties from target proteins. OGT catalyzes the transferal of O-GlcNAc moieties from the donor substrate UDPGlcNAc to proteins and OGA removes the sugar [45]. Thus it can be seen that both OGT and OGA are essential to biological processes in which O-GlcNAc participates and alteration of either of them plays a decisive role in O-GlcNAc-induced carcinogenesis. Actually, deregulation of OGT appears to be an important cause of tumorigenesis and tumor aggravation, as levels of OGT are positively correlated with O-GlcNAcylation in all cancers examined except for live cancer [29, 31, 32, 34-38, 42, 43, 46-48]. Understanding how OGT is regulated will be helpful in 
clarifying the whole process that OGT and subsequent O-GlcNAcylation are involved in cancers. This review highlights findings on OGT regulation, focusing on the regulation of OGT expression, degradation, enzyme activity, substrate selectivity and cellular localization.

\section{FUNCTIONAL ROLE OF OGT AND O-GLCNACYLATION}

Many OGT targets implicated in diversified cellular processes have already been explored and to date, many excellent reviews on O-GlcNAc functions have been published [7, 49-56]. Thus, in this review, the main functions of OGT and O-GlcNAcylation are summarized briefly as follows:

\section{Regulation of transcription}

More than $25 \%$ of O-GlcNAcylated proteins are involved in transcriptional regulation [52]. This modification can affect the functions of transcription factors by several means, including protein-protein interaction (e.g., NF- $\kappa B$, STAT5a, CREB, YY1, PGC$1 \alpha$, etc.), protein stability (e.g., p53, ER- $\alpha$, ER- $\beta$, etc.), nucleo-cytoplasmic translocation (e. g., NeuroD1, CRTC2, NFATc1, Elf-1, etc.), transcriptional activity transactivation (e.g., c-Myc, FoxO1, etc.), DNA binding activity (e.g., Pdx-1, C/EBP $\beta$, etc.) and expression (e.g., MafA, Id2, USF, etc.) [49, 52].

\section{Regulation of epigenetic programmes}

Histones are modified by O-GlcNAc and histone O-GlcNAcylation regulates mitosis, chromatin dynamics and gene expression [28]. Moreover, diverse proteins which are related to the regulation of histone modification and DNA methylation such as HCF-1, EZH2 and TET are regulated by OGT $[28,57-59]$. HCF-1 can interact with several kinds of histone modifying enzymes such as histone methyltransferases MLL5, demethylase LSD1, HATs and HDACs, and recruit these enzymes to chromatin [28]. Recently, OGT is found to promote proteolytic maturation of HCF-1, thus OGT can mediate these histone modifications indirectly via HCF-1 $[60,61]$. EZH 2 is a histone methyltransferase which can catalyze the formation of H3K27me3 by transfering methyl groups to the K27 residue of histone $\mathrm{H} 3$ [62]. OGT interacts with $\mathrm{EZH}$, glycosylates it at Ser75 and improves its protein stability [62]. TET proteins catalyze the hydroxylation of 5-methylcytosine $(5 \mathrm{mC})$ to 5 -hydroxymethylcytosine $(5 \mathrm{hmC})$ and further to 5-formylcytosine $(5 \mathrm{fC})$ and 5-carboxylcytosine $(5 \mathrm{caC})$ [63]. TET1, TET2 and TET3 are all O-GlcNAcylated by OGT and OGT promotes the cytoplasmic relocation of exogenous TET3, the protein stability of TET1 [64]. In turn, TET2 and TET3 recruit OGT to the chromatin and facilitate O-GlcNAcylation of histone H2B $[65,66]$.

\section{Regulation of cell signalling}

O-GlcNAc modification palys a fundamental role in regulating nutrient- and stress-induced signal transduction [67]. The crosstalk between O-GlcNAcylation and O-phosphorylation of proteins controls insulin signalling. Upon insulin stimulation, PIP3 targets AKT and PDK1 to the cell membrane, where AKT is phosphorylated and activated by PDK1. Interestingly, insulin stimulation also causes PIP3 to drive the localization of OGT from the nucleus to the plasma membrane, then OGT is tyrosine phosphorylated by insulin receptor (IR), leading to increase OGT activity [68]. Multiple downstream targets of this signaling pathway including IR- $\beta$, IRS- 1 and AKT, are O-GlcNAcylated and inhibited by activated OGT, resulting in an attenuation of insulin signal transduction $[19,69-71]$.

\section{Response to stress}

Global O-GlcNAc levles are induced by diverse forms of cellular stress; for instance, thermal stress [72]. Knockout of $O G T$ gene using the Cre/loxP system or knockdown of OGT by RNAi reduces cells' tolerance to stress [72]. These findings suggest that O-GlcNAcylation protects cells against stress. O-GlcNAc mediates stress tolerance by different mechanisms, including inhibiting protein degradation or protein deposition [73, 74], inducing the expession of Hsp70 and Hsp40 [72], promoting interactions of Hsp70 with O-GlcNAcylated proteins during stress [23] and reducing capacitive calcium entry [56].

\section{Regulation of cell cycle}

Ogt deletion in mouse embryonic fibroblasts increases levels of p27, a cyclin-dependent kinase inhibitor, blocks cell division and causes cell death [75]. In Hela cells, altered O-GlcNAc level caused by overexpression of OGT or O-GlcNAcase prolongs $\mathrm{M}$ phase, disrupts mitotic phosphorylation and alters the expression of cyclins A and B in the Late M Phase [76]. Raising levels of O-GlcNAc by PUGNAc delays G2/M progression; conversely, lowering O-GlcNAc level by DON (a glutamine fructose-6-amidotransferase inhibitor) promotes the course of cell cycle [76]. Together, these data indicate that O-GlcNAc plays a critical role in cell cycle progression and cell division.

\section{Regulation of O-GIcNAc signalling}

As a nutrient/stress sensor, O-GlcNAc signaling can response to various endogenous and exogenous cues transiently, thus its dynamic process must be controled tightly and temporally. According to various reports, increased O-GlcNAc levels increase OGT expression and decrease OGA expression, suggesting that a feedback loop 
exists to maintain O-GlcNAc homeostasis [77-79]. It can thus be inferred that modulation of gene expression of OGT and OGA is likely to be one mode of moderation for the O-GlcNAc cycling. However, fluctuations in cellular O-GlcNA levels often occur in minutes, which are faster than gene expression regulation $[19,80,81]$. For example, stimulating Jurkat $\mathrm{T}$ cells with $\mathrm{T}$-cell receptor (TCR) for 5-10 $\mathrm{min}$, the O-GlcNAc level of the transcription factor NFATC1 increases 14-fold; similarly, O-GlcNAcmodified NFATc1 levels are rised evidently after 5-10 min in BJAB cells and primary human $\mathrm{T}$ lymphocytes which are stimulated by IgM and TCR respectively [80]. Thus, the factors affecting activities of OGT and OGA such as their posttranslational modifications may be the primary regulators of $\mathrm{O}-\mathrm{GlcNAc}$ signalling under transient response.

\section{FUNCTIONAL SIGNIFICANCE OF OGT AND O-GLCNACYLATION IN NORMAL BIOLOGY}

OGT is found in all metazoans [82]. Ogt-1 is the Caenorhabditis elegans homolog of OGT, and is important for worms' embryogenesis at high temperatures [83]. However, under normal physiological conditions, Ogt-1 is not essential for development and morphogenes of Caenorhabditis elegans [84]. It doesn't mean that OGT is not important in the course of Caenorhabditis elegans' life, because OGT-1 modulates their metabolism and longevity [84-86]. Knockout of ogt-1 in Caenorhabditis elegans suppresses dauer formation and lipid stores [84], elevates trehalose levels and glycogen stores [84], and reduces median adult lifespan $[85,86]$. OGT-1 removal also appears to promote autophagosome maturation in a nutrient-dependent manner [87] and deregulate UV stressand immune-responsive genes $[85,88]$.

Super sex combs (sxc) is the Drosophila homolog of $O G T$, and is necessary for larval development during embryogenesis because $s x c$ mutation in larvae results in posterior displacement of most segments, and no $s x c^{-}$homozygotes can survive beyond the completion of embryogenesis [89]. Maternally rescued sxc- Drosophila which will deplete the maternally supplied $s x c$ several cell divisions later, can grow from the embryonic stage to the pupal stage [89-91], although can not enter the mature period (adults) $[89,92]$. These results indicate that, in Drosophila, OGT is not essential in dividing cells [82].

Different from what we find in Caenorhabditis elegans and Drosophila, OGT is indispensible for cellular viability in mammalian systems and complete knockout of $O G T$ results in embryonic lethality due to incomplete embryogenesis [75, 93]. Conditional knockout of mouse Ogt gene using the Cre/loxP system in thymocytes significantly inhibits the production of mature $\mathrm{T}$ cells and induces apoptosis [75]. Fibroblasts derived from floxed Ogt embryos and transfected with the Cre recombinase to block $O g t$ expression, exhibit no alteration in protein synthesis and degradation, but grow old rapidly and die after 12 days [75]. Neuron-specific knockout of $O g t$ in mice reduces their size, deprives their locomotor activity, increases the level of total tau and hyperphosphorylated tau, and causes death within 10 days of birth [75]. Only $12 \%$ of the cardiomyocyte-specific OGT knockout (cmOGT KO) mice survive to weaning age and only $5 \%$ of male mice survive to adult [94]. Freshly weaned cmOGT KO male mice are observably smaller, undergo fibrotic, dilated cardiomyopathy [94].

\section{ALTERED LEVELS OF OGT AND O-GLCNACYLATION IN CANCERS AND THEIR INVOLVEMENT IN MALIGNANT TRANSFORMATION AND CANCER PROGRESSION}

The contribution function of alterations in O-GlcNAc signaling in the onset, progression and metastasis of cancer has been heavily reported recently [27, 45, 54] (Table 1). Elevated O-GlcNAcylation and OGT levels are existed in breast cancer cell lines and patient tissues [29, 30, 95, 96], and induce tumorigenesis and metastasis via FoxM1 and E-cadherin respectively $[29,30]$. O-GlcNAcylation, OGT and hexosamine biosynthetic pathway (HBP, a branch of glucose metabolism, controls the level of intracellul UDPGlcNAc) related proteins are all up-regulated in prostate cancer tissues [33, 97], and the hyper-O-GlcNAcylation causes invasion through inhibiting the formation of the E-cadherin/catenin complex and inducing the expression of MMP-2 and MMP-9 [32, 33]; in addition, targeting OGT reduces angiogenic potential and VEGF expression via FoxM1 in prostate cancer [32], and increased O-GlcNAc level associates with the poor prognosis of prostate cancer patients [98]. OGT and O-GlcNAcylation elevations are examined in lung and colon cancer tissues and cell lines, and contribute to the etiology and progression of cancer $[34,35]$. Tumor reoccurrence in patients undergoing liver transplantation results in rising O-GlcNAc levels and reducing OGA expression in the cancerous region, but has no significant correlation for OGT levels [36]. Moreover, the migrating and invasive capability of $\mathrm{HepG} 2$ is heightened by elevated O-GlcNAcylation, because this modification decreases E-cadherin expression and increases MMP-1, MMP-2 and MMP-3 expression [36]. OGT mRNA level and protein O-GlcNAc modification are progressively increased during the carcinogenesis of gastric cancer, and patients with hyper-O-GlcNAcylation have poor prognosis $[37,38$, 99]. Reduction of O-GlcNAcylation by OGT siRNA inhbits and increment of this modification by OGA inhibitors enhances cell proliferation and tumor growth of gastric cancer through regulating the activation of ERK signaling pathway and the expression of CDK-2 and cyclin D1 [37]. OGT silencing also induces apoptosis of gastric cancer by inducing the expression of PUMA and cleaved caspase-3 
Table 1: Cancer type-specific expressions and functions of OGT and O-GIcNAcylation

\begin{tabular}{|c|c|c|c|}
\hline cancer type & $\begin{array}{c}\text { OGT/ O-GlcNAc } \\
\text { expression }\end{array}$ & targeted pathways & targeted proteins \\
\hline Breast $[29,30,95,96]$ & $\uparrow / \uparrow$ & tumorigenesis $\uparrow$, metastasis $\uparrow$ & FoxM1 $\uparrow$, E-cadherin $\downarrow$ \\
\hline Prostate $[32,33,97,98]$ & $\uparrow / \uparrow$ & invasion $\uparrow$, angiogenesis $\uparrow$ & $\begin{array}{l}\text { E-cadherin/catenin } \\
\text { MMP- } 2 \uparrow, \text { MMP-9 } 9 \text {, FoxM } 1 \uparrow\end{array}$ \\
\hline Lung [34] & $\uparrow / \uparrow$ & progression $\uparrow$, invasiveness $\uparrow$ & unknown \\
\hline Colon $[34,35]$ & $\uparrow / \uparrow$ & progression $\uparrow$, invasiveness $\uparrow$ & unknown \\
\hline Liver [36] & $-/ \uparrow$ & metastasis $\uparrow$, invasion $\uparrow$ & $\begin{array}{l}\text { E-cadherin } \downarrow, \text { MMP- } 1 \uparrow, \text { MMP- } 2 \uparrow, \\
\text { MMP- } 3 \uparrow\end{array}$ \\
\hline Gastric $[37,38,99,100]$ & $\uparrow / \uparrow$ & $\begin{array}{l}\text { cell viability } \uparrow, \quad \text { apoptosis } \downarrow \text {, } \\
\text { invasion } \uparrow\end{array}$ & $\begin{array}{l}\text { CDK- } 2 \uparrow, \text { cyclin D } 1 \uparrow, \text { pERK } 1 / 2 \uparrow, \\
\text { PUMA } \downarrow \text {, caspase- } 3 \downarrow, \text { pAKT } \uparrow\end{array}$ \\
\hline Pancreatic [31] & $\uparrow / \uparrow$ & cell proliferation $\uparrow$, apoptosis $\downarrow$ & $\mathrm{NF}-\kappa \mathrm{B} \uparrow$ \\
\hline Laryngeal [39] & $\uparrow / \uparrow$ & Tumor growth $\uparrow$, metastasis $\uparrow$ & unknown \\
\hline Bladder [40] & $\uparrow / \uparrow$ & invasion $\uparrow$ & unknown \\
\hline Endometrial [41] & $\uparrow / \uparrow$ & invasion $\uparrow$ & unknown \\
\hline Esophageal [42] & $\uparrow / \uparrow$ & metastasis $\uparrow$ & unknown \\
\hline Anaplastic thyroid [101-103] & unknown & $\begin{array}{l}\text { cell viability } \uparrow, \\
\text { invasion } \uparrow\end{array}$ & $\mathrm{pAKT} \uparrow$ \\
\hline CLL [43] & $\uparrow / \uparrow$ & aggression $\downarrow$ & $\mathrm{pAKT} \downarrow, \mathrm{TNF}-\alpha \downarrow, \mathrm{pJNK} \downarrow$ \\
\hline Ovarian $[48,104,105]$ & $\downarrow / \downarrow$ & migration $\uparrow$, invasion $\uparrow$ & RhoA $\uparrow$, E-cadherin $\downarrow$ \\
\hline
\end{tabular}

pERK1/2, phosphorylated ERK1/2; pAKT, phosphorylated AKT; CLL, chronic lymphocytic leukemia; pJNK, c-Jun N-terminal kinase; -, no change; $\uparrow$, upregulated; $\downarrow$, downregulated.

[99]. Upregulation of O-GlcNAcylation by Thiamet-G, an OGA specific inhibitor, enhances invasion of gastric cancer cells in vitro partially via PI3K/AKT signaling pathway [100]. Increased HBP flux, elevated OGT level and reduced OGA level lead to hyper-O-GlcNAcylation in human pancreatic ductal adenocarcinoma [31]. Downregulation of O-GlcNAcylation via OGT knockdown suppresses cell proliferation in vitro and tumor growth in vivo, and induces apoptosis through decreasing transcriptional activity of NF-кB [31]. The levels of O-GlcNAc, OGT and OGA are all up-regulated in laryngeal cancer tissues, and they boost tumor enlargement and lymph node metastasis, indicating that hyper-O-GlcNAcylation acts as a poor prognostic marker [39]. The mRNA expression of OGT in bladder cancer patients is higher that that in healthy persons, and the OGT level is positively related to degree of histological differentiation (grade II and III > grade I) [40]. Moreover, hyper-O-GlcNAcylation may trigger invasion of bladder cancers because the amount of OGT expressed in invasive or advanced cancers is larger than that expressed in early cancers [40]. Similar phenomena is identified in endometrial cancer, that the expression of OGT and OGA is visibly higher in tumors of grade II and III than in grade I, and they contribute to myometrial invasion [41]. Compared to the normal tissues, OGT and O-GlcNAcation are higher in esophageal squamous cell carcinoma samples [42]. Although OGT expression isn't discovered clear correlation with tumor size, the clinical stage and metastatic lymph nodes, O-GlcNAcation level is higher in esophageal squamous cell carcinoma tissues with lymph node metastasis [42]. Changes in O-GlcNAc, OGT and OGA in anaplastic thyroid cancer have not been described, however several research groups have found that increased O-GlcNAcation is closely related to the development of this cancer [101-103]; Krzeslak et al. showed that upregulation of O-GlcNAc level by PUGNAc or OGA siRNA increased cell proliferation of anaplastic thyroid cancer via the stimulation of IGF-1/AKT1/GSK3 $\beta /$ cyclin D1 pathway partially [101]; Cheng and colleagues determined that O-GlcNAcylation enhanced not only cell proliferation but also colony formation ability, migration and invasion of anaplastic thyroid cancer cells in vitro [102], and Zhang et al. observed that elevated O-GlcNAcylation acquired by OGA inhibition or OGT overexpression induced the invasion of anaplastic thyroid cancer cells rather than cell proliferation partially by PI3K/AKT signaling [103]. Increased O-GlcNAcylation, OGT and UDP-GlcNAc levels are also detected in lymphocytes of chronic lymphocytic leukemia patients [43]; unlike what we have obtained in above-mentioned tumor types, higher O-GlcNAc levels in chronic lymphocytic leukemia patients depress CD38 expression, prolong ymphocyte doubling times and indicate a relatively good prognosis [43]. Distinguishingly, O-GlcNAcylation is decreased in ovarian tumors compared with normal tissue [104]; however, O-GlcNAcylation augments the migration and invasion of SKOV3 and 59M 
ovarian cancer cells via the RhoA/ROCK/MLC signaling pathway [105] or E-cadherin [48].

\section{REGULATION OF OGT EXPRESSION AND PROTEIN STABILITY IN NORMAL CELLS}

\section{Transcription}

In colon macrophages, the transcription factor Nrf2 binds to the $O G T$ promoter region and increases gene transcription [106]. Elevated OGT protein mediates the up-regulation of STAT3 O-GlcNAcylation at Thr717 and this modification leads to decreased STAT3 phosphorylation, which is accompanied by exacerbated colonic inflammation and inflammation-driven tumorigenesis [106]. Interestingly, Cullin-3 can depress Nrf2-induced OGT expression via Nrf2 degradation, inhibit STAT3 O-GlcNAcylation, promote STAT3 phosphorylation correspondingly and then protect against intestinal inflammation [106].

\section{Post-transcription}

Several miRNAs have been validated to interact with 3'-UTRs of OGT mRNAs and lead to the suppression of OGT expression [107, 108]. MiR-423-5p can induce apoptosis of cardiomyocytes through binding to OGT mRNA and decreasing OGT protein level [107]. miR$15 \mathrm{~b}$ has also been described as negative regulator of OGT [108]; Liu et al. documented that miR-15b can target OGT and inhibit O-GlcNAcylation of NF-kB, resulting in differentiation suppression of Th17 cells both in vivo and in vitro [108].

\section{Protein stability}

OGT is observed to interacts with the tetratricopeptide repeat binding site of $\mathrm{Hsp} 90$ in endothelial cells and inhibition of Hsp90 destabilizes OGT and enhances its degradation by the proteasome [109]; however, the precise mechanism underlying Hsp90-induced OGT protein stability remains unclear. Hypoxia or hypoxia-mimetic agents can reduce OGT protein levels rather than its gene expression to induce endothelial inflammatory response [110]; hypoxia stimulates generation of ROS/RNS which heightens $26 \mathrm{~S}$ proteasome activity [110]; activated $26 \mathrm{~S}$ proteasome works in coordination with E3 ubiquitin ligase $\beta$-TrCP1 to achieve proteasomal degradation of OGT [110].

\section{Unknown mechanisms}

In human aortic smooth muscle cells, high glucose increases OGT expression, however $\mathrm{Cr}^{3+}$ significantly inhibites glucose-induced OGT expression and exhibits antioxidant and antiproliferative effects [111].

\section{REGULATION OF OGT EXPRESSION AND PROTEIN STABILITY IN CANCER}

\section{Transcription}

The elevation of OGT mRNA levels in non-small cell lung cancer and prostate cancer cells is partly due to the hyper-activated MAPK/ERK signaling [112]. Over-expression of constitutively activated MEK1DD induces OGT transcription via transcription factor Elk1 , while suppression of MAPK/ERK signaling by a MEK inhibitor U0126 greatly reduces OGT mRNA level [112]. Moreover, elevated O-GlcNAcylation rescues the inhibitory effect of ERK inactivation on cell proliferation and clone-forming ability of H1299 cells [112]. In 293T cells, E2F1 transcription factor can directly bind to the $O G T$ promoter and repress endogenous OGT protein level and RB1 is required for E2F1-mediated suppression. [113]. It is reported that glucose deprivation increases protein O-GlcNAcylation through up-regulation of OGT in cancerous cells [78, 79, 114]; Cheung et al. discovered that, in Neuro-2a neuroblastoma cells, the increase of OGT mRNA and protein expression induced by glucose deprivation was due to the activation of AMPK [77]; however, Taylor et al. found that, in contrast to HepG2 cells cultured under normal condition, glucose-treated HepG2 cells expressed increased OGT through decreasing hexosamine flux rather than activating AMPK pathway $[78,79]$.

\section{Protein stability}

OGT protein can be degraded by the ubiquitinproteasome pathway and the autophagy pathway [60, $109,110,115]$. As mentioned earlier, beyond its wellknown role as the O-GlcNAc transferase, OGT also can hydrolyze HCF-1 to achieve the maturation of HCF-1 [60, 61]. HCF-1, in turn, stabilizes OGT against proteasomal degradation in several kinds of tumor cells [60] (Figure 1A). Nearly one half of the total nuclear OGT forms stable complexes with HCF-1 in Hela cells [60]. And a positive correlation exists between HCF-1 and OGT protein levels; a decrease in HCF-1 leads to a decrease in OGT, correspondingly, an increase in HCF-1 causes an increase in OGT [60]. The change in OGT levels caused by HCF-1 is not at the level of mRNA or promoter but at the protein level [60]. The above results suggest that HCF1 inhibits protein degradation of OGT. Deubiquitinating enzyme BAP1 is mutated in diverse malignant tumors [116]. Strikingly, Bap1 deletion can decrease the levels of OGT and HCF-1, suggesting that BAP1 is propitious to stabilize these epigenetic regulators [116]. Studies show that BAP1 not only stabilizes HCF-1 by preventing HCF1 proteasomal degradation, but also deubiquitinates and stabilizes OGT. Together, BAP1, HCF-1 and OGT can 
form a ternary complex to preserve normal hematopoiesis by recruiting additional histone-modifying enzymes to regulate gene expression [116]. PI3K/AKT/mTOR pathway stimulates the expression of OGT and the level of global O-GlcNAcylation in breast and live cancer cells $[115,117]$. This pathway increases the expression of the oncogenic transcription factor c-Myc which induces the transcription of Hsp90 in breast cancer [117]; Hsp90 interacts with OGT and inhibits its proteasomal degradation, which is consistent with previous findings in endothelial cells [117] (Figure 1B). In addition to by the proteasome pathway, PI3K/AKT/mTOR pathway also can promote OGT degradation by the autophagy pathway, although the underlying mechanism is not fully clear $[115$, 117]. The histone demethylase LSD2 can perform as an E3 ubiquitin ligase to promote proteasome-dependent degradation of OGT [118] (Figure 1C). Overespression of LSD2 increases the ubiquitination of OGT in 293T and H1299 cells [118]. Reduction of LSD2 by shRNA promotes colony-forming ability of 293T and H1299 cells via OGT inhibition, and up-regulation of OGT rescues LSD2-inhibited cell growth [118].

\section{Unknown mechanisms}

As described above, a variety of stimuli can induce OGT and O-GlcNAc levels by unknown molecular mechanisms $[55,72]$. Insulin can stimulate the expression of OGT [119] [120] and enhances cytosolic staining of OGT [119] in H-411E and HepG2 hepatoma cells. In addition, rapidly elevated global O-GlcNAcylation displays a feedback inhibition of OGT levels in several types of cancer cells $[18,76,82,121]$; pharmacologic inhibition of OGT leads to OGT protein levels either remain constant [122] or increase slightly [123]; correspondingly, pharmacologic inhibition of OGA results in a decrease of OGT at protein levels rather than at mRNA level in HeLa cervical carcinoma, SHSY5Y neuroblastoma, and K562 leukemia cells [121]. Information on how the global O-GlcNAcylation regulates OGT is limited, appearing to regulate OGT's protein stability.

\section{REGULATION OF OGT GLYCOSYLTR ANSFERASE FUNCTIONS IN NORMAL CELLS}

\section{UDP-GIcNAc}

UDP-GlcNAc is an end product of HBP and acts as the donor substrate of OGT. Its levels are responsive to flux through metabolic pathways of glucose, nucleotide, fatty acid and amino acid [124-126]. UDP-GlcNAc concentration dominates the affinity of OGT for peptides $[2,127,128]$; in vitro studies show that, aiming at different protein substrates of OGT, UDP-GlcNAc displays different values of $\mathrm{Km}$; for example, the $\mathrm{Km}$ values of UDP-GlcNAc for Nup62 and CaMKIV are about $1 \mu \mathrm{M}$ and $25 \mu \mathrm{M}$ respectively $[129,130]$. This phenomenon may be explained at least partly by the contact mode exhibited in the crystal structures between UDP-GlcNAc and protein substrates. Structural analyses show that UDP-GlcNAc and protein substrate bind to OGT in an ordered sequential manner, and UDP-GlcNAc combines with OGT firstly then the target protein binds to the amino acids surrounding the UDP-binding cleft subsequently [126]. Thus, UDP-GlcNAc which has binded to OGT preferentially may alter the three-dimensional structure of OGT which affects the subsequent binding of protein substrates.

\section{AMPK}

Pharmacological and genetic inactivation of AMPK in endothelial cells or knock out of AMPK in mice increases 26S proteasome activity [131]. Conversely, activation of AMPK effectively suppresses $26 \mathrm{~S}$ proteasomes [131]. The inhibition of 26S proteasome caused by AMPK activation is realized through increasing the interaction between $26 \mathrm{~S}$ proteasome and OGT which can O-GlcNAcylate $26 \mathrm{~S}$ proteasome and suppress its assembly and activity [131]. In general, these data show that AMPK regulates OGT by some ill-defined mechanism and further blocks the proteasome [131]. As reported, compared with undifferentiated myoblastic cells, differentiated myotubes display a significant increase OGT localized in cytoplasmic [132]. However, activated AMPK can directly phosphorylate OGT at Thr444 [132, 133] and OGT Thr444 phosphorylation increases its nuclear localization [132].

\section{Insulin}

Insulin triggers the tyrosine phosphorylation of OGT in T3-L1 adipocytes, probably through stimulating the interaction of OGT with PDK1 [69], and results in the increase of catalytic activity and nucleo-cytoplasmic translocation of OGT [68]. In addition, insulin treatment of 3T3-L1 adipocytes also stimulates self-GlcNAcylation of OGT and this modification may also contribute to the activity of OGT [68].

\section{Salts}

OGT activity and its affinity for UDP-GlcNAc can be restrained by several salts [134-136]. The inhibitory effects of $\mathrm{NaCl}, \mathrm{KCl}$, and $\mathrm{NaH}_{2} \mathrm{PO} 4$ have be determined and $\mathrm{IC}_{50}$ values of them are 45,50 , and $4 \mathrm{mM}$ individually $[134,135]$. Another study extends this observation by revealing that $\mathrm{Na}_{3} \mathrm{VO}_{4}$ is more potent in inhibiting OGT activity $\left(\mathrm{IC}_{50}\right.$ of $55 \mu \mathrm{M}$ in brain cytosol and $150 \mu \mathrm{M}$ in nucleosol) [136]. 


\section{REGULATION OF OGT GLYCOSYLTR ANSFERASE FUNCTIONS IN CANCER}

\section{UDP-GIcNAc}

Oxidative phosphorylation replaced by aerobic glycolysis (the Warburg effect) is one of the critical features in cancer [137]. The product of aerobic glycolysis, acetyl-CoA, is required to biosynthesize UDP-GlcNAc. Thus, this especial metabolic model of cancer causes an increase in flux through the HBP $[45,138]$. As mentioned above, besides glucose flux, amino acid flux, especially glutamine can remarkably affect the concentration of intracellular UDP-GlcNAc levels. Interestingly, cancer cells have a clear preference for glutamine and glutamine consumption in cancer cells is much higher than that in normal cells [139], thereby letting glutamine be the other major metabolic material into the HBP. Actually, elevated HBP flux and HBP related enzymes have been confirmed to contribute to hyper-O-GlcNAcylation in human tumors, suggesting that an increase in UDP-GlcNAc level might an incentive to the hyper-O-GlcNAcylation in cancer cells $[31,33,97]$.

\section{Protein interactions}

OGT associates with multiple protein partners and the interactions influence OGT's substrate selectivity, chromatin association, cellular localization and glycosyltransferase activiity (Table 2). It has well-documented that OGT's substrate selectivity is altered by associations with the mitochondrial trafficking protein Trak1, the transcriptional corepressor $\mathrm{mSin} 3 \mathrm{~A}$, the transcriptional coactivator PGC- $1 \alpha$, the subunit of myosin phosphatase MYPT1, the arginine methyltransferase CARM1 and the kinases p38MAPK and AMPK. Trak1 (previously known as OIP106) interacts with the tetratricopeptide repeats (TPRs) of OGT [140, 141]. Meanwhile, Trak1 has been verified to localize to nucleus and co-localize with RNA polymerase II in Hela cells [140, 141]. These results suggest that Trak1 may recuit OGT to the promoter of different genes for O-GlcNAcylation of RNA polymerase II and transcription factors [140, 141]. A specific interaction between the OGT (TPR 1-6) region and the mSin3A PAH4 domain (amino acids 888-967) is ascertained in HepG2 cells [142, 143]. MSin3A also can draw OGT to chromatin to depress the activity of RNA polymerase II and transcription factors by O-GlcNAc modification, which plays a synergistic role with histone deacetylation to silence gene expression $[142,143]$. Under hyperglycemic conditions, the interaction between PGC- $1 \alpha$ and OGT boosts the O-GlcNAc modification of the transcription factor FoxO1 [144, 145]. MYPT1 and CARM1 both interact with OGT and a mutual regulation is existed between them; OGT can O-GlcNAcylate MYPT1 and CARM1 and moderates their activity, MYPT1 and CARM1 in turn affect OGT substrate specificity in vitro [146]. And besides, MYPT1 knockdown by siRNA results in changes in O-GlcNAcylation of partial proteins in Neuro-2a neuroblastoma cells, indicating that MYPT1 decides OGT substrate specificity in vivo [146]. OGT interacts directly with p38MAPK using its C terminus; although p38MAPK don't phosphorylate OGT, it can target OGT to specific targets, including neurofilament $\mathrm{H}$ under the condition of glucose starvation in Neuro2a neuroblastoma cells [77]. As we know, AMPK phosphorylates OGT at Thr444 and increases its nuclear localization in non-tumor tissues (myotubes) [132]. Similarly, AMPK also phosphorylates OGT at Thr444 in $293 \mathrm{~T}$ and HepG2 cells $[132,133]$. Differently, phosphorylation of OGT at Thr444 triggered by AMPK in tumor cells alters the substrate selectivity of OGT [132] and reduces its affinity for chromatin, thereby suppressing O-GlcNAcylation of histone H2B and downstream gene expression [133]. The chromatin localization of OGT is regulated not only by AMPK, but also TETs and OGA. TETs associate with OGT at transcription starting sites and facilitate OGT localization on chromatin [65, 147-150]. TET2 directly interacts with OGT in vivo, despite their specific interactions doesn't alter the enzymatic activity of TET2, they are propitious to OGT-dependent histone O-GlcNAcylation [147-149]. TET3 is reported to interact with OGT via its $\mathrm{H}$ domain and stabilizes the protein levels of OGT, the stabilization of OGT protein enhances its recruitment to chromatin [65, 148-150]. OGA and OGT can associate strongly through specific domains and this OGA-OGT complex locates to repressed promoters [151]. LXR, PIP3 and Aurora B regulate OGT activity through affecting its cellular localization. The interaction of LXR and OGT increases the nuclear location of OGT and that LXRs deficiency strikingly reduces nuclear O-GlcNAc signaling [152]. After induction with insulin, PIP3 interact with the phosphoinositide-interaction domain of OGT (PPO) and facilitates the nuclearcytoplasmic transport of OGT, then OGT catalyses dynamic O-GlcNAcylation of insulin signaling related proteins at the plasma membrane [19, 120]. Extensive research data show that dynamic O-GlcNAc cycling controls cellular growth [75, 76, 153-155]. Interestingly, in mammalian cells OGT localizes to the mitotic spindle at $\mathrm{M}$ phase and during cytokinesis OGT relocates to the midbody [76]. Further studies in Hela cells show that during cytokinesis, OGT forms a transient complex with PP1, OGA, and Aurora B at the midbody [156]. The activity of Aurora B, which is an essential regulator of mitotic progression, determines correct cellular localization of this quaternary complex because Aurora $\mathrm{B}$ repression blocks localization of the complex to the midbody [156]. The quaternary complex can regulate 
Table 2: OGT-interacting partner in cancer

\begin{tabular}{|c|c|c|}
\hline Partner & Binding location of $\mathrm{OGT}^{\mathrm{a}}$ & Function \\
\hline Trak1 $[140,141]$ & TPRs $2-6$ & recruits OGT to RNA polymerase II and transcription factors \\
\hline $\operatorname{mSin} 3 \mathrm{~A}[142,143]$ & TPR $1-6$ & targets OGT to transcription factors and RNA polymerase II \\
\hline PGC-1 $\alpha[144,145]$ & unknown & facilitates OGT activity on the transcription factor FoxO1 \\
\hline MYPT1 [146] & unknown & enhances OGT substrate specificity in vivo \\
\hline CARM1 [146] & unknown & increases OGT substrate specificity in vitro \\
\hline p38MAPK [77] & C- Terminus (979-1036 aa) & targets OGT to neurofilament $\mathrm{H}$ \\
\hline AMPK $[132,133]$ & unknown & $\begin{array}{l}\text { alters the substrate selectivity of OGT and promotes its dissociation } \\
\text { from chromatin }\end{array}$ \\
\hline TET 2 [147-149] & TPR5 and 6 & enhances the chromatin association of OGT in vivo \\
\hline TET $3[65,148-150]$ & The N- and C-terminal regions & enhances OGT's recruitment to chromatin \\
\hline OGA [151] & N- Terminus (1-286 aa) & colocalizes in the repressed promoters \\
\hline LXR [152] & unknown & colocalizes in the nucleus \\
\hline PIP3 $[19,120]$ & C- Terminus (958-1001 aa) & recruits OGT from the nucleus to the plasma membrane \\
\hline Aurora B [156] & unknown & translocates OGT to the midbody during cytokinesis \\
\hline URI [157] & unknown & inhibits OGT activity in vitro and in vivo \\
\hline
\end{tabular}

aMost binding locations, specifically the listed regions of OGT, have not been localized, thus, these locations provide an upper bound of the binding region; aa, Amino acid.

both the O-GlcNAcylation and phosphorylation state of midbody substrates vimentin at $\mathrm{M}$ phase [156]. Finally, URI, OGT and PP $1 \gamma$ can form a heterotrimeric complex [157]. Glucose deprivation induces the phosphorylation of URI at Ser-371 and the release of PP1 $\gamma$ from the complex and then promotes URImediated OGT inhibition, resulting in a decrease of c-Myc-dependent survival [157]. These results show that OGT associates with and is regulated in different ways by distrinct groups of binding partners in response to distrinct signals, which may provide reasons why no conservel sequence motifs involved in the peptide substrate binding is founs in OGT protein.

\section{Post-translational modification}

OGT is modified by phosphorylation $[2,68,81$, 158, 159], O-GlcNAcylation [2, 68, 158, 160-162], S-nitrosylation [158, 163] and ubiquitination [60] (Table 3). All these posttranslational modifications have been proposed to regulate OGT, although the functional sites of these modifications have not been elucidated clearly. Active $\mathrm{Ca}^{2+} / \mathrm{CaMKIV}$ can phosphorylate OGT and then elevate its activity in NG-108-15 cells [81]. Activated AMPK can directly phosphorylate OGT at Thr444 [132, 133] and OGT Thr444 phosphorylation does not alter the enzymatic activity of OGT, but promotes its dissociation from chromatin and alters its substrate selectivity in 293T, HepG2 and HeLa cells [132, 133] (mentioned in "Protein interactions" sections). OGT is found to be phosphorylated on Ser3 or Ser4 (data could not distinguish between these potential sites) by GSK3 $\beta$ and the phosphorylation enhances OGT activity [159]. Interestingly, Mass Spectrometer analysis also reveals that both Ser3 and Ser4 of OGT can be O-GlcNAc modified. Hence, phosphorylation by GSK3 $\beta$ and O-GlcNAcylation must compete with and regulate each other at this N-terminal site of OGT [159]. Seo et al. identified that Ser389 is the major O-GlcNAc modification site of OGT, this O-GlcNAc modification doesn't alter the enzyme activity and protein-protein interaction but regulates the nuclear localization of OGT through exposure of hidden NLS of OGT and its association with Importin $\alpha 5$ and $\beta$ [164]. In resting cells, OGT is S-nitrosylated, however the innate immune response induced by LPS can trigger its denitrosylation and heighten its catalytic activity [163]. As mentioned above, HCF-1 can stabilize OGT and this process is achieved through inhibiting the ubiquitination of OGT which leads to its proteasomal degradation [60].

Besides the moderators mentioned above, stress stimulation also affects the activity of OGT. Thermal stress increases the activity of OGT remarkably by currently unknown mechanisms [72] and facilitates OGT to translocate from cytoplasm to the nucleus [18].

\section{THERAPEUTIC EFFECTS OF OGT MODULATION}

Exploring credible biomarkers for diagnosis, prognosis, and confirmation of recurrence is a critical aspect of treating human cancer. In fact, 
Table 3: Regulation of OGT glycosyltransferase functions by post-translational modification in cancer

\begin{tabular}{|c|c|c|c|}
\hline $\begin{array}{l}\text { Post-translational } \\
\text { modifications }\end{array}$ & Sites & Regulator & Functions \\
\hline \multirow{3}{*}{ Phosphorylation } & unknown & $\mathrm{Ca}^{2+} / \mathrm{CaMKIV}$ & activates OGT activity [81] \\
\hline & $\mathrm{S} 3 / \mathrm{S} 4$ & GSK3 $\beta$ & enhances OGT activity [159] \\
\hline & T444 & AMPK & $\begin{array}{l}\text { promotes OGT's dissociation from chromatin and alters } \\
\text { its substrate selectivity }[132,133]\end{array}$ \\
\hline \multirow[t]{2}{*}{ O-GlcNAcylation } & S3\& S4 & OGT & $\begin{array}{l}\text { competes with phosphorylation by GSK3 } \beta \text { and regulates } \\
\text { each other [159] }\end{array}$ \\
\hline & S389 & OGT & regulates the nuclear localization of OGT [164] \\
\hline S-nitrosylation & unknown & NO & decreases catalytic activity of OGT in resting cells [163] \\
\hline Ubiquitination & unknown & Ubiquitin ligase E3 & leads to OGT's proteasomal degradation [60] \\
\hline
\end{tabular}

NO, nitric oxide.

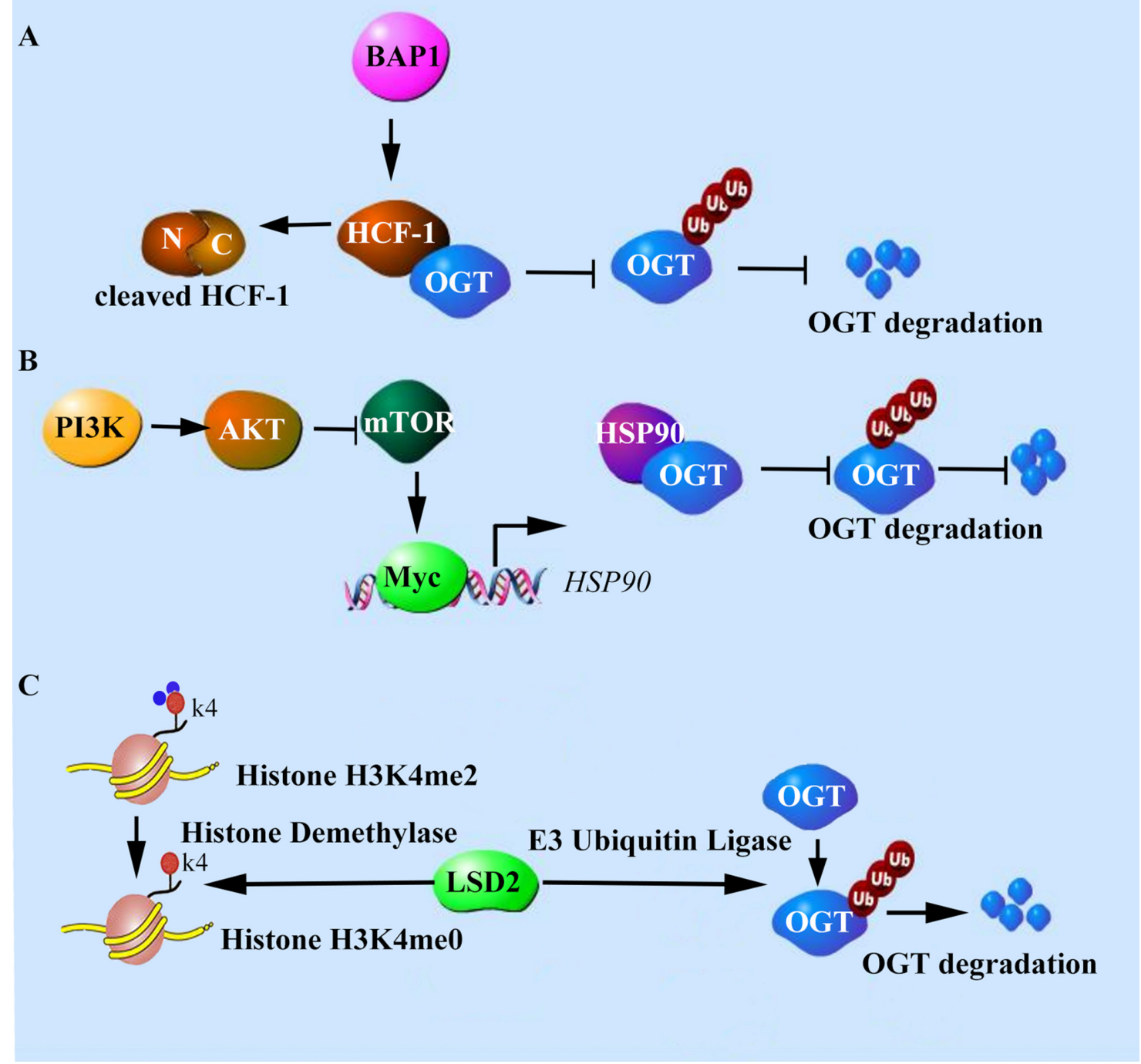

Figure 1: Regulation of OGT stability in cancer OGT catalyzes site-specific proteolysis of HCF-1, and HCF-1, in turn, stabilizes OGT against proteasomal degradation. BAP1 promotes the interaction between HCF-1 and OGT (A) Hsp90 associates with OGT and inhibits its proteasomal degradation, and this process is enhanced by the PI3K/mTOR/Myc pathway (B) LSD2 not only is a well-known histone $\mathrm{H} 3 \mathrm{~K} 4 \mathrm{me} 1 / \mathrm{me} 2$ demethylase but also can promote ubiquitylation and degradation of OGT as an E3 ubiquitin ligase (C). 
Table 4: The available OGT inhibitors

\begin{tabular}{|c|c|c|c|}
\hline Categories & Compound & $\mathrm{IC}_{50}$ & Advantages and limitations \\
\hline \multirow{6}{*}{$\begin{array}{l}\text { Substrate and product } \\
\text { analogues }\end{array}$} & $\mathrm{C}-\mathrm{UDP}^{\mathrm{b}}[165]$ & $9 \mu \mathrm{M}$ & lack of cell permeability \\
\hline & UDP-S-GlcNAcc [165] & $93 \mu \mathrm{M}$ & \multirow{2}{*}{ lack of cell permeability } \\
\hline & UDP-C-GlcNAc ${ }^{c}[165]$ & $41 \mu \mathrm{M}$ & \\
\hline & Ac4-5S-GlcNAc $[31,120,123,167]$ & $5 \mu \mathrm{M}$ & $\begin{array}{l}\text { cell-permeable, but reduces intracellular pool } \\
\text { of UDP-GlcNAc }\end{array}$ \\
\hline & Alloxan $^{\mathrm{d}}[168-172]$ & $18 \mu \mathrm{M}$ & $\begin{array}{l}\text { cell-permeable, but has potential off-target } \\
\text { effects and general cellular toxicity }\end{array}$ \\
\hline & $\operatorname{BADGP}^{\mathrm{e}}[173,174]$ & unknown & reducing intracellular pool of UDP-GlcNAc \\
\hline \multirow{3}{*}{ HTS-derived inhibitora } & ST045849 [175-178] & $53 \mu \mathrm{M}$ & having potential toxic and off-target effects \\
\hline & BZX $[29,97,175]$ & $10 \mu \mathrm{M}$ & \\
\hline & OSMI-1 $[122,179]$ & $2.7 \mu \mathrm{M}$ & \multirow{3}{*}{ lack of cell permeability } \\
\hline \multirow{2}{*}{ Bisubstrate inhibitors } & goblin 1 [180] & $18 \mu \mathrm{M}$ & \\
\hline & goblin 2 [180] & unknown & \\
\hline
\end{tabular}

ahigh-throughput screening-derived inhibitors; b UDP analogue; c UDP-GlcNAc analogues; d Uracil analogue; e GalNAc analogue.

hyper-O-GlcNAcylation has been detected in many different types of cancer and contributes to the formation and progression of tumors. As the unique O-GlcNAc transferase, OGT is elevated together with O-GlcNAcylation in almost all cancers examined. An inhibition of OGT results in a corresponding downregulation of tumor cell survival rate, division and invasion [31]. Thus, discovering the specific inhibitor of OGT will be conducive to further comprehensive elucidation of the biological function of O-GlcNAcylation and may obtain a potential therapeutic agentia against cancer.

In fact, in the last 15 years, researchers have discovered and designed several categories of OGT inhibitors (Table 4). The first category means the donor substrate and product analogues. UDP, as a product of O-GlcNAcylation processes, can inhibit OGT in vitro with an $\mathrm{IC}_{50}$ of $1.8 \mu \mathrm{M}[165,166]$. Unfortunately, it is inapposite for cell biology researches because it is unable to cross cellular membranes and is a substrate for extensive other enzymes. Then C-UDP, a UDP minic, is discovered and reported to perturb O-GlcNAc in vitro $\left(\mathrm{IC}_{50}=9 \mu \mathrm{M}\right)$ [165]. Moreover, two UDP-GlcNAc analogues UDP-S-GlcNAc $\left(\mathrm{IC}_{50}=93 \mu \mathrm{M}\right)$ and UDPC-GlcNAc $\left(\mathrm{IC}_{50}=41 \mu \mathrm{M}\right)$ are demonstrated to inhibit OGT activity [165]. However, the three compounds are also not cell-penetrant. Substrate analogue $\mathrm{Ac}_{4}-5 \mathrm{~S}$ GlcNAc $\left(\mathrm{IC}_{50}=5 \mu \mathrm{M}\right)$ is cell-permeable and has been used in a number of studies [31, 120,123,167], but the main pitfall of it is that it depresses the intracellular deposits of UDP-GlcNAc by impeding the HBP [122]. The uracil analogue alloxan $\left(\mathrm{IC}_{50}=18 \mu \mathrm{M}\right)$ was the first OGT inhibitor reported and is cell-permeable
[168-171]. Sadly, alloxan has potential off-target effects and general cellular toxicity [172]. Finally, a $\mathrm{N}$-acetylgalactosamine (GalNAc) mimic, BADGP, is shown to target OGT usually but suppresses the flux of the HBP [173, 174]. The second category is highthroughput screening-derived inhibitors, such as ST045849 $\left(\mathrm{IC}_{50}=53 \mu \mathrm{M}\right)[175], \mathrm{BZX}\left(\mathrm{IC}_{50}=10 \mu \mathrm{M}\right)$ [175] and OSMI-1 $\left(\mathrm{IC}_{50}=2.7 \mu \mathrm{M}\right)$ [122]. ST045849 (also named compound 4 ) is used to prove the function of O-GlcNAcylation in pancreatic $\beta$-cell development [176], insulin production [176], gluconeogenesis [177], embryonic stem cell self-renewal [177], and protein stability [178]. BZX (also named compound 5 ) has been used to test if O-GlcNAcylation induces growth and invasion in breast cancer cells [29] and if the stability of the oncogene c-Myc is controled by O-GlcNAcylation in human prostate cell lines [97]. OSMI-1 decreases global O-GlcNAc levels in various mammalian cell lines [122] and has recently been used to discuss the effects of O-GlcNAc in the reproduction of Herpes Simplex Virus [179]. Unfortunately, these compounds also have potential toxic and off-target effects. Bisubstrate inhibitors, including goblin $1\left(\mathrm{IC}_{50}\right.$ $=18 \mu \mathrm{M})$ and goblin 2, are the third categories [180]. They are designed by replacing the GlcNAc moiety of UDP-GlcNAc with an acceptor peptide, aiming to achieve selective inhibition. The major current limitation with this class of compounds is the lack of cell permeability. Based on the above analysis, future work requires optimizing the current tools or creating novel molecules to gain a cell-permeable, specific OGT inhibitor which is apropriate for laboratory experiments and even clinical cancer therapy. 


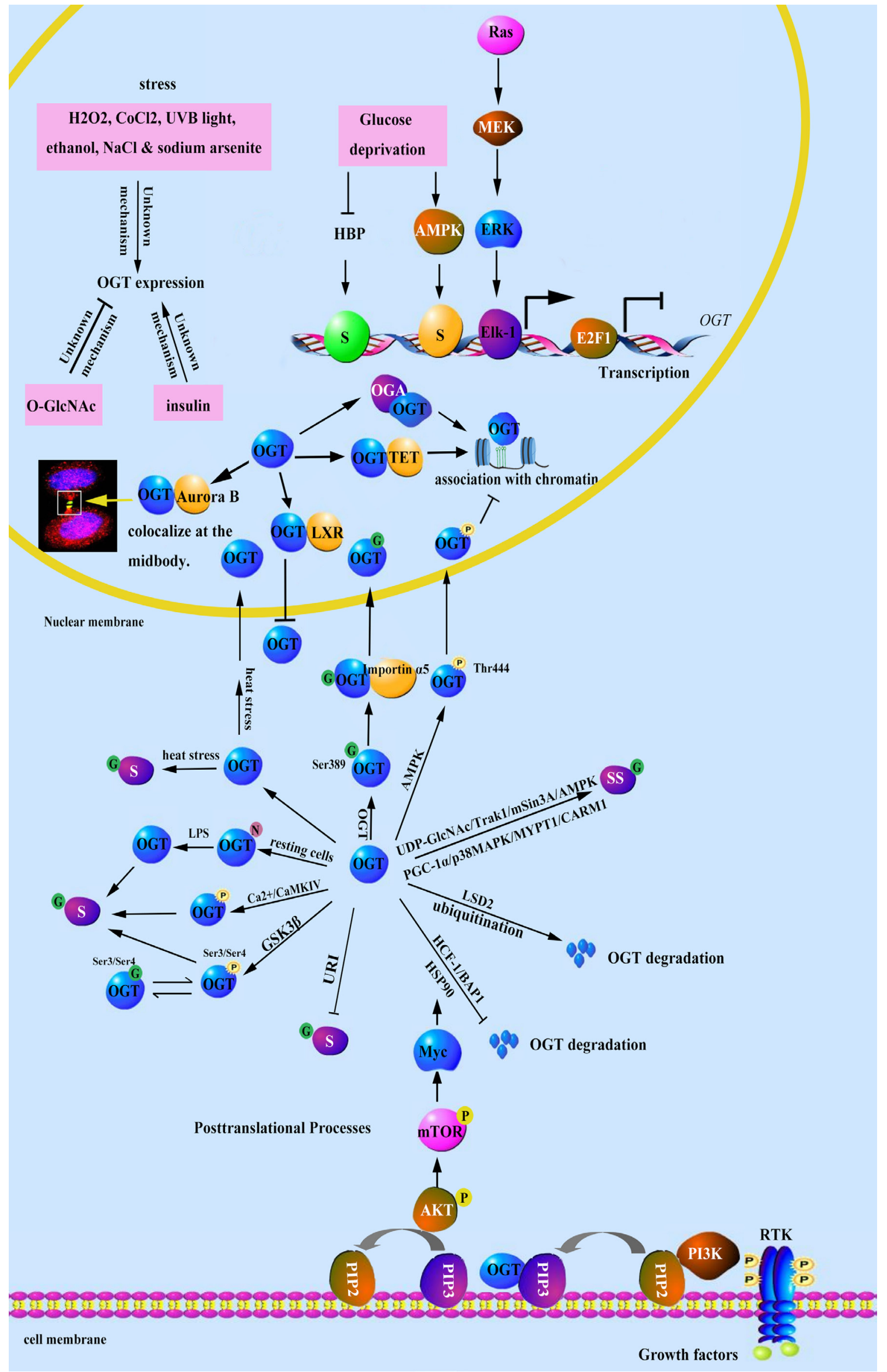


Figure 2: Schematic illustration of mechanisms of regulation of OGT expression and enzyme functions in cancer OGT expression is inhibited by E2F1 and increased by Elk-1 and glucose deprivation at the transcriptional level; MAPK/ ERK signaling induces OGT via Elk-1; glucose deprivation increases OGT mRNA levels via the activation of AMPK or decreased hexosamine fluxs. OGT protein degradation is suppressed by HCF-1, BAP1 and PI3K/mTOR /Myc/Hsp90 pathway, and triggered by LSD2. In additon, OGT level can be induced by several forms of stress, insulin and global O-GlcNAcylation by unknown mechanisms. OGT's substrate selectivity is altered by UDP-GlcNAc, Trak1, mSin3A, PGC-1 $\alpha$, p38MAPK, AMPK, MYPT1 and CARM1. The cellular localization of OGT is regulated by AMPK, TET, OGA, LXR, PIP3 and Aurora B; AMPK decreases OGT localization on chromatin; TET family and OGA facilitate OGT localization on chromatin; LXR and OGT colocalize in the nucleus; PIP3 recruits OGT to the plasma membrane; Aurora B translocates OGT to the midbody during cytokinesis. URI associates with OGT and mediates OGT inhibition. OGT is modified by phosphorylation, O-GlcNAcylation, S-nitrosylation and ubiquitination. OGT is phosphorylated and activated by active $\mathrm{Ca} 2+/ \mathrm{CaMKIV}$ in vitro and GSK3 $\beta$ (at S3 or S4) in vivo. AMPK phosphorylates OGT at Thr444 and promotes its dissociation from chromatin and alters its substrate selectivity. O-GlcNAcylation of OGT at S3 and S4 competes with phosphorylation by GSK3 $\beta$. O-GlcNAc modification of OGT at Ser389 regulates the nuclear localization of OGT through exposure of hidden NLS of OGT and its association with Importin $\alpha 5$ and $\beta$. OGT is S-nitrosylated in resting cells and its denitrosylation following induction of the innate immune response results in increased catalytic activity. The ubiquitination of OGT leads to its proteasomal degradation. Finally, heat stress can increase the activity of OGT and promotes the translocation to the nucleus. HBP, Hexosamine Biosynthesis Pathway; S, substrate; G, O-GlcNacylation; P, phosphorylation; SS, Specific substrate; N, S-nitrosylation; Ub, Ubiquitination.

\section{CONCLUSIONS}

In the last 30 years, extremly large number of publications have elaborated the significance of O-GlcNAc in manifold cellular functions and diseases. Deregulation of O-GlcNAcylation is an event detected in a variety of cancer types and this aberrant O-GlcNAcylation is conducive to tumorigenesis, cell proliferation, invasion and metastasis, and resists to therapy. Considering the modification's involvement in cancer, OGT has become attractive candidates for pharmacological targeting. However, the research on the regulatory mechanism of OGT is still in the early stage. In this review, we summarize the regulation of OGT expression and glycosyltransferase functions in cancer (Figure 2). OGT can be regualted by multiple ways to increase cell growth and survival, including OGT expression, degradation, localization and posttranslational modification. Interestingly, a large proportion of the moderators of OGT are also the downstream targets of OGT, such as Trak1 $[140,141], \mathrm{mSin} 3 \mathrm{~A}[142,143]$, PGC- $1 \alpha[144,145]$, HCF1 [60, 61], TET2/3 [65, 147-150], c-Myc [181], MYPT1 [146], CARM1 [146], 26S proteasome [131], AMPK [132] and GSK3 $\beta$ [129]. This endows it with the ability to regulate cellular physiology in a feedback loop. The existing research results show that the regulation of OGT is extremely complicated and OGT operates as a central hub for controlling multiple important physiological processes such as metabolism and cell cycle progression.

\section{Abbreviations}

O-GlcNAc, O-linked $\quad \beta$-D-N-acetylglucosamine; OGT, O-GlcNAc transferase; UDP-GlcNAc, Uridine 5'-diphosphate N-acetylglucosamine; OGA, O-GlcNAcase; ER- $\alpha / \beta$, Estrogen Receptor $\alpha / \beta$; NeuroD1, neurogenic differentation 1; CRTC2, transducer of regulated cyclic adenosine monophosphate response element-binding protein; NFATc1, nuclear factor of activated T-cells, cytoplasmic, calcineurin-dependent 1; Elf-1, E74-like factor 1; Pdx-1, pancreatic and duodenal homeobox 1; C/ EBP $\beta$, CCAAT enhancer-binding protein; MafA, v-maf musculoaponeurotic fibrosarcoma oncogene homolog A; Id2, inhibitor of differentiation 2; HCF-1, Host Cell Factor 1; EZH2, enhancer of zeste homolog 2; TET, ten-eleven translocation enzymes; MLL5, Mixed lineage leukemia 5; HATs, histone acetyltransferases; HDACs, histone deacetylases; FoxM1, forkhead box M1; MMP-1/-2/-3/9, matrix metalloproteinase-1/-2/-3/-9; VEGF, vascular endothelial growth factor; $\mathrm{CDK}-2$, cyclin dependent kinase 2; PUMA, BCL2 binding component 3; RhoA, ras homolog family member A; ROCK, Rho-associated protein kinase; MLC, myosin light chain; PDK1, 3-phosphoinositidedependent kinase 1; IRS-1, insulin receptor substrate 1; Cre, Cyclization Recombination Enzyme; MEK1DD: an activated mutant of MEK1, with serine to aspartic acid substitutions at residues Ser218 and Ser222; Elk-1, ETS domain-containing protein; RB1, Retinoblastomaassociated protein 1; Nrf2, NF-E2 related factor 2; AMPK, AMP-activated protein kinase; miRNA, microRNA; Hsp90, heat shock protein 90; ROS/RNS, reactive oxygen or nitrogen species; $\beta$ - $\operatorname{TrCP} 1, \beta$-transducin repeat-containing protein 1; LSD2, Lysine-specific histone demethylase 1B; Nup62, Nuclear pore glycoprotein p62; CaMKIV, calcium/calmodulin-dependent protein kinase IV; Trak1, trafficking kinesin protein 1; LPS, lipopolysaccharide; PGC-1 $\alpha$, Peroxisome proliferator-activated receptor gamma coactivator 1-alpha; FoxO1, Forkhead box protein O1; MYPT1, myosin phosphatase target subunit 1; CARM1, coactivator associated arginine methyltransferase 1; LXR, Liver X receptor; PIP3, Phosphatidylinositol 3,4,5-triphosphate; URI, prefoldin like chaperone; PP1 $\gamma$, protein phosphatase 1 catalytic subunit gamma; GSK3 $\beta$, Glycogen synthase kinase-3 beta; NLS, Nuclear localization sequence; Importin $\alpha 5$, Importin subunit alpha-5; BADGP, benzyl-N-acetyl- $\alpha$-Dgalactosaminide (GalNAc $\alpha$-O-benzyl); ST045849, 3-(2-adamantanylethyl)-2-[(4-chlorophenyl) azamethylene]-4-oxo-1, 3-thiazaperhyd roine-6-carboxylic acid; BZX, 4-methoxyphenyl 6-acetyl-2-oxobenzo [d] oxazole-3 (2H)-carboxylate. 


\section{ACKNOWLEDGMENTS AND FUNDING}

This work was supported by the Qingdao Postdoctoral Application Research Project (grant numbers 2015, 172).

\section{CONFLICTS OF INTEREST}

The authors declare that they have no conflicts of interest.

\section{REFERENCES}

1. Hart GW, Haltiwanger RS, Holt GD, Kelly WG. Nucleoplasmic and cytoplasmic glycoproteins. Ciba Found Symp. 1989; 145:102-112, discussion 112-108.

2. Kreppel LK, Blomberg MA, Hart GW. Dynamic glycosylation of nuclear and cytosolic proteins. Cloning and characterization of a unique O-GlcNAc transferase with multiple tetratricopeptide repeats. J Biol Chem. 1997; 272:9308-15.

3. Lubas WA, Frank DW, Krause M, Hanover JA. O-Linked GlcNAc transferase is a conserved nucleocytoplasmic protein containing tetratricopeptide repeats. J Biol Chem. 1997; 272:9316-24.

4. Gao Y, Wells L, Comer FI, Parker GJ, Hart GW. Dynamic O-glycosylation of nuclear and cytosolic proteins: cloning and characterization of a neutral, cytosolic beta-Nacetylglucosaminidase from human brain. J Biol Chem. 2001; 276:9838-45.

5. Wells L, Gao Y, Mahoney JA, Vosseller K, Chen C, Rosen A, Hart GW. Dynamic O-glycosylation of nuclear and cytosolic proteins: further characterization of the nucleocytoplasmic beta-N-acetylglucosaminidase, O-GlcNAcase. J Biol Chem. 2002; 277:1755-61.

6. Ma J, Hart GW. O-GlcNAc profiling: from proteins to proteomes. Clin Proteomics. 2014; 11:8.

7. Bond MR, Hanover JA. A little sugar goes a long way: the cell biology of O-GlcNAc. J Cell Biol. 2015; 208:869-80.

8. Lewis BA, Burlingame AL, Myers SA. Human RNA Polymerase II Promoter Recruitment in Vitro Is Regulated by O-Linked N-Acetylglucosaminyltransferase (OGT). J Biol Chem. 2016; 291:14056-61.

9. Lu L, Fan D, Hu CW, Worth M, Ma ZX, Jiang J. Distributive O-GlcNAcylation on the Highly Repetitive C-Terminal Domain of RNA Polymerase II. Biochemistry. 2016; 55:1149-58.

10. Gambetta MC, Müller J. A critical perspective of the diverse roles of O-GlcNAc transferase in chromatin. Chromosoma. 2015; 124:429-42.

11. Zhu G, Tao T, Zhang D, Liu X, Qiu H, Han L, Xu Z, Xiao Y, Cheng C, Shen A. O-GlcNAcylation of histone deacetylases 1 in hepatocellular carcinoma promotes cancer progression. Glycobiology. 2016; 26:820-33.

12. Dentin R, Hedrick S, Xie J, Yates J 3rd, Montminy M. Hepatic glucose sensing via the CREB coactivator CRTC2. Science. 2008; 319:1402-05.
13. Ruan HB, Han X, Li MD, Singh JP, Qian K, Azarhoush S, Zhao L, Bennett AM, Samuel VT, Wu J, Yates JR 3rd, Yang X. O-GlcNAc transferase/host cell factor $\mathrm{C} 1$ complex regulates gluconeogenesis by modulating PGC- $1 \alpha$ stability. Cell Metab. 2012; 16:226-37.

14. Ma Z, Vosseller K. O-GlcNAc in cancer biology. Amino Acids. 2013; 45:719-33.

15. Ruan HB, Dietrich MO, Liu ZW, Zimmer MR, Li MD, Singh JP, Zhang K, Yin R, Wu J, Horvath TL, Yang X. O-GlcNAc transferase enables AgRP neurons to suppress browning of white fat. Cell. 2014; 159:306-17.

16. Yi W, Clark PM, Mason DE, Keenan MC, Hill C, Goddard WA 3rd, Peters EC, Driggers EM, Hsieh-Wilson LC. PFK1 Glycosylation Is a Key Regulator of Cancer Cell Growth and Central Metabolic Pathways. Science. 2012; 337:975-980.

17. Zachara NE, Hart GW. O-GlcNAc a sensor of cellular state: the role of nucleocytoplasmic glycosylation in modulating cellular function in response to nutrition and stress. Biochim Biophys Acta. 2004; 1673:13-28.

18. Kazemi Z, Chang H, Haserodt S, McKen C, Zachara NE. O-linked beta-N-acetylglucosamine (O-GlcNAc) regulates stress-induced heat shock protein expression in a GSK3beta-dependent manner. J Biol Chem. 2010; 285:39096107.

19. Yang X, Ongusaha PP, Miles PD, Havstad JC, Zhang F, So WV, Kudlow JE, Michell RH, Olefsky JM, Field SJ, Evans RM. Phosphoinositide signalling links O-GlcNAc transferase to insulin resistance. Nature. 2008; 451:964-69.

20. Vaidyanathan K, Wells L. Multiple tissue-specific roles for the O-GlcNAc post-translational modification in the induction of and complications arising from type II diabetes. J Biol Chem. 2014; 289:34466-71.

21. Han I, Kudlow JE. Reduced O glycosylation of Sp1 is associated with increased proteasome susceptibility. Mol Cell Biol. 1997; 17:2550-58.

22. Zhang F, Su K, Yang X, Bowe DB, Paterson AJ, Kudlow JE. O-GlcNAc modification is an endogenous inhibitor of the proteasome. Cell. 2003; 115:715-25.

23. Guinez C, Lemoine J, Michalski JC, Lefebvre T. 70-kDaheat shock protein presents an adjustable lectinic activity towards O-linked N-acetylglucosamine. Biochem Biophys Res Commun. 2004; 319:21-26.

24. Zhu Y, Liu TW, Cecioni S, Eskandari R, Zandberg WF, Vocadlo DJ. O-GlcNAc occurs cotranslationally to stabilize nascent polypeptide chains. Nat Chem Biol. 2015; 11:319-25.

25. Hart GW, Slawson C, Ramirez-Correa G, Lagerlof O. Cross talk between O-GlcNAcylation and phosphorylation: roles in signaling, transcription, and chronic disease. Annu Rev Biochem. 2011; 80:825-58.

26. Jóźwiak P, Forma E, Bryś M, Krześlak A. O-GlcNAcylation and Metabolic Reprograming in Cancer. Front Endocrinol (Lausanne). 2014; 5:145.

27. de Queiroz RM, Carvalho E, Dias WB. O-GlcNAcylation: The Sweet Side of the Cancer. Front Oncol. 2014; 4:132. 
28. Singh JP, Zhang K, Wu J, Yang X. O-GlcNAc signaling in cancer metabolism and epigenetics. Cancer Lett. 2015; 356:244-50.

29. Caldwell SA, Jackson SR, Shahriari KS, Lynch TP, Sethi G, Walker S, Vosseller K, Reginato MJ. Nutrient sensor $\mathrm{O}-\mathrm{GlcNAc}$ transferase regulates breast cancer tumorigenesis through targeting of the oncogenic transcription factor FoxM1. Oncogene. 2010; 29:2831-42.

30. Gu Y, Mi W, Ge Y, Liu H, Fan Q, Han C, Yang J, Han F, Lu $\mathrm{X}, \mathrm{Yu}$ W. GlcNAcylation plays an essential role in breast cancer metastasis. Cancer Res. 2010; 70:6344-51.

31. Ma Z, Vocadlo DJ, Vosseller K. Hyper-O-GlcNAcylation is anti-apoptotic and maintains constitutive NF- $\kappa \mathrm{B}$ activity in pancreatic cancer cells. J Biol Chem. 2013; 288:15121-30.

32. Lynch TP, Ferrer CM, Jackson SR, Shahriari KS, Vosseller K, Reginato MJ. Critical role of O-Linked $\beta$-N-acetylglucosamine transferase in prostate cancer invasion, angiogenesis, and metastasis. J Biol Chem. 2012; 287:11070-81.

33. Gu Y, Gao J, Han C, Zhang X, Liu H, Ma L, Sun X, Yu W. O-GlcNAcylation is increased in prostate cancer tissues and enhances malignancy of prostate cancer cells. Mol Med Rep. 2014; 10:897-904.

34. Mi W, Gu Y, Han C, Liu H, Fan Q, Zhang X, Cong Q, $\mathrm{Yu}$ W. O-GlcNAcylation is a novel regulator of lung and colon cancer malignancy. Biochim Biophys Acta. 2011; 1812:514-19.

35. Yehezkel G, Cohen L, Kliger A, Manor E, Khalaila I. O-linked $\beta$-N-acetylglucosaminylation (O-GlcNAcylation) in primary and metastatic colorectal cancer clones and effect of $\mathrm{N}$-acetyl- $\beta$-D-glucosaminidase silencing on cell phenotype and transcriptome. J Biol Chem. 2012; 287:28755-69.

36. Zhu Q, Zhou L, Yang Z, Lai M, Xie H, Wu L, Xing C, Zhang F, Zheng S. O-GlcNAcylation plays a role in tumor recurrence of hepatocellular carcinoma following liver transplantation. Med Oncol. 2012; 29:985-93.

37. Jiang M, Qiu Z, Zhang S, Fan X, Cai X, Xu B, Li X, Zhou J, Zhang X, Chu Y, Wang W, Liang J, Horvath T, et al. Elevated O-GlcNAcylation promotes gastric cancer cells proliferation by modulating cell cycle related proteins and ERK 1/2 signaling. Oncotarget. 2016; 7:61390-402. https:// doi.org/10.18632/oncotarget.11359.

38. Jang TJ, Kim UJ. O-GlcNAcylation is associated with the development and progression of gastric carcinoma. Pathol Res Pract. 2016; 212:622-30.

39. Starska K, Forma E, Brzezińska-Błaszczyk E, LewyTrenda I, Bryś M, Jóźwiak P, Krześlak A. Gene and protein expression of O-GlcNAc-cycling enzymes in human laryngeal cancer. Clin Exp Med. 2015; 15:455-68.

40. Rozanski W, Krzeslak A, Forma E, Brys M, Blewniewski M, Wozniak P, Lipinski M. Prediction of bladder cancer based on urinary content of MGEA5 and OGT mRNA level. Clin Lab. 2012; 58:579-83.
41. Krześlak A, Wójcik-Krowiranda K, Forma E, Bieńkiewicz A, Bryś M. Expression of genes encoding for enzymes associated with O-GlcNAcylation in endometrial carcinomas: clinicopathologic correlations. Ginekol Pol. 2012; 83:22-26.

42. Qiao Z, Dang C, Zhou B, Li S, Zhang W, Jiang J, Zhang J, Kong R, Ma Y. O-linked N-acetylglucosamine transferase (OGT) is overexpressed and promotes O-linked protein glycosylation in esophageal squamous cell carcinoma. J Biomed Res. 2012; 26:268-73.

43. Shi Y, Tomic J, Wen F, Shaha S, Bahlo A, Harrison R, Dennis JW, Williams R, Gross BJ, Walker S, Zuccolo J, Deans JP, Hart GW, Spaner DE. Aberrant O-GlcNAcylation characterizes chronic lymphocytic leukemia. Leukemia. 2010; 24:1588-98.

44. Ma Z, Vosseller K. Cancer metabolism and elevated O-GlcNAc in oncogenic signaling. J Biol Chem. 2014; 289:34457-65.

45. Banerjee PS, Lagerlöf O, Hart GW. Roles of O-GlcNAc in chronic diseases of aging. Mol Aspects Med. 2016; 51:1-15.

46. Krześlak A, Forma E, Bernaciak M, Romanowicz H, Bryś $\mathrm{M}$. Gene expression of O-GlcNAc cycling enzymes in human breast cancers. Clin Exp Med. 2012; 12:61-65.

47. Jang TJ. Differential membranous E-cadherin expression, cell proliferation and O-GlcNAcylation between primary and metastatic nodal lesion in colorectal cancer. Pathol Res Pract. 2016; 212:113-19.

48. Jin FZ, Yu C, Zhao DZ, Wu MJ, Yang Z. A correlation between altered O-GlcNAcylation, migration and with changes in E-cadherin levels in ovarian cancer cells. Exp Cell Res. 2013; 319:1482-90.

49. Yang X, Qian K. Protein O-GlcNAcylation: emerging mechanisms and functions. Nat Rev Mol Cell Biol. 2017; $18: 452-65$.

50. Janetzko J, Walker S. The making of a sweet modification: structure and function of O-GlcNAc transferase. J Biol Chem. 2014; 289:34424-32.

51. Vaidyanathan K, Durning S, Wells L. Functional O-GlcNAc modifications: implications in molecular regulation and pathophysiology. Crit Rev Biochem Mol Biol. 2014; 49:140-63.

52. Ozcan S, Andrali SS, Cantrell JE. Modulation of transcription factor function by O-GlcNAc modification. Biochim Biophys Acta. 2010; 1799:353-64.

53. Harwood KR, Hanover JA. Nutrient-driven O-GlcNAc cycling - think globally but act locally. J Cell Sci. 2014; 127:1857-67.

54. Fardini $\mathrm{Y}$, Dehennaut $\mathrm{V}$, Lefebvre $\mathrm{T}$, Issad $\mathrm{T}$. O-GlcNAcylation: A New Cancer Hallmark? Front Endocrinol (Lausanne). 2013; 4:99.

55. Butkinaree C, Park K, Hart GW. O-linked beta-Nacetylglucosamine (O-GlcNAc): extensive crosstalk with phosphorylation to regulate signaling and transcription in response to nutrients and stress. Biochim Biophys Acta. 2010; 1800:96-106. 
56. Zachara NE, Hart GW. Cell signaling, the essential role of O-GlcNAc! Biochim Biophys Acta. 2006; 1761:599-617.

57. Hanover JA, Krause MW, Love DC. Bittersweet memories: linking metabolism to epigenetics through O-GlcNAcylation. Nat Rev Mol Cell Biol. 2012; 13:31221.

58. Dehennaut V, Leprince D, Lefebvre T. O-GlcNAcylation, an Epigenetic Mark. Focus on the Histone Code, TET Family Proteins, and Polycomb Group Proteins. Front Endocrinol (Lausanne). 2014; 5:155.

59. Lewis BA, Hanover JA. O-GlcNAc and the epigenetic regulation of gene expression. J Biol Chem. 2014; 289:34440-48.

60. Daou S, Mashtalir N, Hammond-Martel I, Pak H, Yu H, Sui G, Vogel JL, Kristie TM, Affar B. Crosstalk between O-GlcNAcylation and proteolytic cleavage regulates the host cell factor-1 maturation pathway. Proc Natl Acad Sci USA. 2011; 108:2747-52.

61. Capotosti F, Guernier S, Lammers F, Waridel P, Cai Y, Jin J, Conaway JW, Conaway RC, Herr W. O-GlcNAc transferase catalyzes site-specific proteolysis of HCF-1. Cell. 2011; 144:376-88.

62. Chu CS, Lo PW, Yeh YH, Hsu PH, Peng SH, Teng YC, Kang ML, Wong CH, Juan LJ. O-GlcNAcylation regulates EZH2 protein stability and function. Proc Natl Acad Sci USA. 2014; 111:1355-60.

63. Ciesielski P, Jozwiak P, Krzeslak A. [TET proteins and epigenetic modifications in cancers]. [Article in Polish]. Postepy Hig Med Dosw. 2015; 69:1371-83.

64. Dassanayaka S, Jones SP. O-GlcNAc and the cardiovascular system. Pharmacol Ther. 2014; 142:62-71.

65. Zhang Q, Liu X, Gao W, Li P, Hou J, Li J, Wong J. Differential regulation of the ten-eleven translocation (TET) family of dioxygenases by O-linked $\beta-\mathrm{N}$-acetylglucosamine transferase (OGT). J Biol Chem. 2014; 289:5986-96.

66. Shi FT, Kim H, Lu W, He Q, Liu D, Goodell MA, Wan M, Songyang $\mathrm{Z}$. Ten-eleven translocation 1 (Tet1) is regulated by O-linked $\mathrm{N}$-acetylglucosamine transferase (Ogt) for target gene repression in mouse embryonic stem cells. J Biol Chem. 2013; 288:20776-84.

67. Zeidan Q, Hart GW. The intersections between O-GlcNAcylation and phosphorylation: implications for multiple signaling pathways. J Cell Sci. 2010; 123:13-22.

68. Whelan SA, Lane MD, Hart GW. Regulation of the O-linked beta-N-acetylglucosamine transferase by insulin signaling. J Biol Chem. 2008; 283:21411-17.

69. Whelan SA, Dias WB, Thiruneelakantapillai L, Lane MD, Hart GW. Regulation of insulin receptor substrate 1 (IRS1)/AKT kinase-mediated insulin signaling by O-Linked beta-N-acetylglucosamine in 3T3-L1 adipocytes. J Biol Chem. 2010; 285:5204-11.

70. Vosseller K, Wells L, Lane MD, Hart GW. Elevated nucleocytoplasmic glycosylation by O-GlcNAc results in insulin resistance associated with defects in Akt activation in 3T3-L1 adipocytes. Proc Natl Acad Sci USA. 2002; 99:5313-18.

71. Soesanto YA, Luo B, Jones D, Taylor R, Gabrielsen JS, Parker G, McClain DA. Regulation of Akt signaling by O-GlcNAc in euglycemia. Am J Physiol Endocrinol Metab. 2008; 295:E974-80.

72. Zachara NE, O'Donnell N, Cheung WD, Mercer JJ, Marth JD, Hart GW. Dynamic O-GlcNAc modification of nucleocytoplasmic proteins in response to stress. A survival response of mammalian cells. J Biol Chem. 2004; 279:30133-42.

73. Sohn KC, Lee KY, Park JE, Do SI. OGT functions as a catalytic chaperone under heat stress response: a unique defense role of OGT in hyperthermia. Biochem Biophys Res Commun. 2004; 322:1045-51.

74. Mer G, Hietter H, Lefèvre JF. Stabilization of proteins by glycosylation examined by NMR analysis of a fucosylated proteinase inhibitor. Nat Struct Biol. 1996; 3:45-53.

75. O'Donnell N, Zachara NE, Hart GW, Marth JD. Ogtdependent $\mathrm{X}$-chromosome-linked protein glycosylation is a requisite modification in somatic cell function and embryo viability. Mol Cell Biol. 2004; 24:1680-90.

76. Slawson C, Zachara NE, Vosseller K, Cheung WD, Lane MD, Hart GW. Perturbations in O-linked beta-Nacetylglucosamine protein modification cause severe defects in mitotic progression and cytokinesis. J Biol Chem. 2005; 280:32944-56.

77. Cheung WD, Hart GW. AMP-activated protein kinase and $\mathrm{p} 38$ MAPK activate O-GlcNAcylation of neuronal proteins during glucose deprivation. J Biol Chem. 2008; 283:13009-20.

78. Taylor RP, Parker GJ, Hazel MW, Soesanto Y, Fuller W, Yazzie MJ, McClain DA. Glucose deprivation stimulates O-GlcNAc modification of proteins through up-regulation of O-linked N-acetylglucosaminyltransferase. J Biol Chem. 2008; 283:6050-57.

79. Taylor RP, Geisler TS, Chambers JH, McClain DA. Upregulation of O-GlcNAc transferase with glucose deprivation in HepG2 cells is mediated by decreased hexosamine pathway flux. J Biol Chem. 2009; 284:3425-32.

80. Golks A, Tran TT, Goetschy JF, Guerini D. Requirement for O-linked N-acetylglucosaminyltransferase in lymphocytes activation. EMBO J. 2007; 26:4368-79.

81. Song M, Kim HS, Park JM, Kim SH, Kim IH, Ryu SH, Suh PG. o-GlcNAc transferase is activated by CaMKIVdependent phosphorylation under potassium chlorideinduced depolarization in NG-108-15 cells. Cell Signal. 2008; 20:94-104.

82. Levine ZG, Walker S. The Biochemistry of O-GlcNAc Transferase: Which Functions Make It Essential in Mammalian Cells? Annu Rev Biochem. 2016; 85:631-57.

83. Radermacher PT, Myachina F, Bosshardt F, Pandey R, Mariappa D, Müller HA, Lehner CF. O-GlcNAc reports ambient temperature and confers heat resistance on ectotherm development. Proc Natl Acad Sci USA. 2014; 111:5592-97. 
84. Hanover JA, Forsythe ME, Hennessey PT, Brodigan TM, Love DC, Ashwell G, Krause M. A Caenorhabditis elegans model of insulin resistance: altered macronutrient storage and dauer formation in an OGT-1 knockout. Proc Natl Acad Sci USA. 2005; 102:11266-71.

85. Love DC, Ghosh S, Mondoux MA, Fukushige T, Wang P, Wilson MA, Iser WB, Wolkow CA, Krause MW, Hanover JA. Dynamic O-GlcNAc cycling at promoters of Caenorhabditis elegans genes regulating longevity, stress, and immunity. Proc Natl Acad Sci USA. 2010; 107:7413-18.

86. Rahman MM, Stuchlick O, El-Karim EG, Stuart R, Kipreos ET, Wells L. Intracellular protein glycosylation modulates insulin mediated lifespan in C.elegans. Aging (Albany NY). 2010; 2:678-90. https://doi.org/10.18632/aging.100208.

87. Guo B, Liang Q, Li L, Hu Z, Wu F, Zhang P, Ma Y, Zhao B, Kovács AL, Zhang Z, Feng D, Chen S, Zhang H. O-GlcNAcmodification of SNAP-29 regulates autophagosome maturation. Nat Cell Biol. 2014; 16:1215-26.

88. Bond MR, Ghosh SK, Wang P, Hanover JA. Conserved nutrient sensor O-GlcNAc transferase is integral to C. elegans pathogen-specific immunity. PLoS One. 2014; 9:e113231.

89. Ingham PW. A gene that regulates the bithorax complex differentially in larval and adult cells of Drosophila. Cell. 1984; 37:815-23.

90. Gambetta MC, Oktaba K, Muller J. Essential role of the glycosyltransferase sxc/Ogt in polycomb repression. Science. 2009; 325:93-96.

91. Sinclair DA, Syrzycka M, Macauley MS, Rastgardani T, Komljenovic I, Vocadlo DJ, Brock HW, Honda BM. Drosophila O-GlcNAc transferase (OGT) is encoded by the Polycomb group (PcG) gene, super sex combs (sxc). Proc Natl Acad Sci USA. 2009; 106:13427-32.

92. Bainbridge SP, Bownes M. Staging the metamorphosis of Drosophila melanogaster. J Embryol Exp Morphol. 1981; 66:57-80.

93. Shafi R, Iyer SP, Ellies LG, O’Donnell N, Marek KW, Chui D, Hart GW, Marth JD. The O-GlcNAc transferase gene resides on the $\mathrm{X}$ chromosome and is essential for embryonic stem cell viability and mouse ontogeny. Proc Natl Acad Sci USA. 2000; 97:5735-39.

94. Watson LJ, Long BW, DeMartino AM, Brittian KR, Readnower RD, Brainard RE, Cummins TD, Annamalai L, Hill BG, Jones SP. Cardiomyocyte Ogt is essential for postnatal viability. Am J Physiol Heart Circ Physiol. 2014; 306:H142-53.

95. Champattanachai V, Netsirisawan $P$, Chaiyawat $P$, Phueaouan T, Charoenwattanasatien R, Chokchaichamnankit D, Punyarit P, Srisomsap C, Svasti J. Proteomic analysis and abrogated expression of O-GlcNAcylated proteins associated with primary breast cancer. Proteomics. 2013; 13:2088-99.

96. Kebede M, Ferdaoussi M, Mancini A, Alquier T, Kulkarni RN, Walker MD, Poitout V. Glucose activates free fatty acid receptor 1 gene transcription via phosphatidylinositol-3- kinase-dependent O-GlcNAcylation of pancreas-duodenum homeobox-1. Proc Natl Acad Sci USA. 2012; 109:2376-81.

97. Itkonen HM, Minner S, Guldvik IJ, Sandmann MJ, Tsourlakis MC, Berge V, Svindland A, Schlomm T, Mills IG. O-GlcNAc transferase integrates metabolic pathways to regulate the stability of c-MYC in human prostate cancer cells. Cancer Res. 2013; 73:5277-87.

98. Kamigaito T, Okaneya T, Kawakubo M, Shimojo H, Nishizawa O, Nakayama J. Overexpression of O-GlcNAc by prostate cancer cells is significantly associated with poor prognosis of patients. Prostate Cancer Prostatic Dis. 2014; 17:18-22.

99. Wen T, Hou K, Li Z, Li L, Yu H, Liu Y, Li Y, Yin Z. Silencing $\beta$-linked $\mathrm{N}$-acetylglucosamine transferase induces apoptosis in human gastric cancer cells through PUMA and caspase-3 pathways. Oncol Rep. 2015; 34:3140-46.

100. Zhang N, Chen X. Potential role of O-GlcNAcylation and involvement of PI3K/Akt1 pathway in the expression of oncogenic phenotypes of gastric cancer cells in vitro. Biotechnol Appl Biochem. 2016; 63:841-51.

101. Krześlak A, Jóźwiak P, Lipińska A. Down-regulation of $\beta-\mathrm{N}-$ acetyl-D-glucosaminidase increases Akt1 activity in thyroid anaplastic cancer cells. Oncol Rep. 2011; 26:743-49.

102. Cheng YU, Li H, Li J, Li J, Gao Y, Liu B. O-GlcNAcylation enhances anaplastic thyroid carcinoma malignancy. Oncol Lett. 2016; 12:572-78.

103. Zhang P, Wang C, Ma T, You S. O-GlcNAcylation enhances the invasion of thyroid anaplastic cancer cells partially by PI3K/Akt1 pathway. Onco Targets Ther. 2015; 8:3305-13.

104. de Queiroz RM, Madan R, Chien J, Dias WB, Slawson C. Changes in O-Linked N-Acetylglucosamine (O-GlcNAc) Homeostasis Activate the p53 Pathway in Ovarian Cancer Cells. J Biol Chem. 2016; 291:18897-914.

105. Niu Y, Xia Y, Wang J, Shi X. O-GlcNAcylation promotes migration and invasion in human ovarian cancer cells via the RhoA/ROCK/MLC pathway. Mol Med Rep. 2017; 15:2083-89.

106. Li X, Zhang Z, Li L, Gong W, Lazenby AJ, Swanson BJ, Herring LE, Asara JM, Singer JD, Wen H. Myeloidderived cullin 3 promotes STAT3 phosphorylation by inhibiting OGT expression and protects against intestinal inflammation. J Exp Med. 2017; 214:1093-109.

107. Luo P, He T, Jiang R, Li G. MicroRNA-423-5p targets O-GlcNAc transferase to induce apoptosis in cardiomyocytes. Mol Med Rep. 2015; 12:1163-68.

108. Liu R, Ma X, Chen L, Yang Y, Zeng Y, Gao J, Jiang W, Zhang F, Li D, Han B, Han R, Qiu R, Huang W, et al. MicroRNA15b Suppresses Th17 Differentiation and Is Associated with Pathogenesis of Multiple Sclerosis by Targeting O-GlcNAc Transferase. J Immunol. 2017; 198:2626-39.

109. Zhang F, Snead CM, Catravas JD. Hsp90 regulates O-linked $\beta-\mathrm{N}$-acetylglucosamine transferase: a novel mechanism of modulation of protein $\mathrm{O}$-linked $\beta-\mathrm{N}$-acetylglucosamine modification in endothelial cells. Am J Physiol Cell Physiol. 2012; 302:C1786-96. 
110. Liu H, Wang Z, Yu S, Xu J. Proteasomal degradation of O-GlcNAc transferase elevates hypoxia-induced vascular endothelial inflammatory response. Cardiovasc Res. 2014; 103:131-39.

111. Ganguly R, Sahu S, Chavez RJ, Raman P. Trivalent chromium inhibits TSP-1 expression, proliferation, and O-GlcNAc signaling in vascular smooth muscle cells in response to high glucose in vitro. Am J Physiol Cell Physiol. 2015; 308:C111-22.

112. Zhang X, Ma L, Qi J, Shan H, Yu W, Gu Y. MAPK/ERK signaling pathway-induced hyper-O-GlcNAcylation enhances cancer malignancy. Mol Cell Biochem. 2015; 410:101-10.

113. Muthusamy S, Hong KU, Dassanayaka S, Hamid T, Jones SP. E2F1 Transcription Factor Regulates O-linked $\mathrm{N}$-acetylglucosamine (O-GlcNAc) Transferase and O-GlcNAcase Expression. J Biol Chem. 2015; 290:31013-24.

114. Love DC, Kochan J, Cathey RL, Shin SH, Hanover JA. Mitochondrial and nucleocytoplasmic targeting of O-linked GlcNAc transferase. J Cell Sci. 2003; 116:647-54.

115. Park S, Pak J, Jang I, Cho JW. Inhibition of mTOR affects protein stability of OGT. Biochem Biophys Res Commun. 2014; 453:208-12.

116. Dey A, Seshasayee D, Noubade R, French DM, Liu J, Chaurushiya MS, Kirkpatrick DS, Pham VC, Lill JR, Bakalarski CE, Wu J, Phu L, Katavolos P, et al. Loss of the tumor suppressor BAP1 causes myeloid transformation. Science. 2012; 337:1541-46.

117. Sodi VL, Khaku S, Krutilina R, Schwab LP, Vocadlo DJ, Seagroves TN, Reginato MJ. mTOR/MYC Axis Regulates O-GlcNAc Transferase Expression and O-GlcNAcylation in Breast Cancer. Mol Cancer Res. 2015; 13:923-33.

118. Yang Y, Yin X, Yang H, Xu Y. Histone demethylase LSD2 acts as an E3 ubiquitin ligase and inhibits cancer cell growth through promoting proteasomal degradation of OGT. Mol Cell. 2015; 58:47-59.

119. Majumdar G, Wright J, Markowitz P, Martinez-Hernandez A, Raghow R, Solomon SS. Insulin stimulates and diabetes inhibits O-linked $\mathrm{N}$-acetylglucosamine transferase and O-glycosylation of Sp1. Diabetes. 2004; 53:3184-92.

120. Perez-Cervera Y, Dehennaut V, Aquino Gil M, Guedri K, Solórzano Mata CJ, Olivier-Van Stichelen S, Michalski JC, Foulquier F, Lefebvre T. Insulin signaling controls the expression of O-GlcNAc transferase and its interaction with lipid microdomains. FASEB J. 2013; 27:3478-86.

121. Zhang Z, Tan EP, VandenHull NJ, Peterson KR, Slawson C. O-GlcNAcase Expression is Sensitive to Changes in O-GlcNAc Homeostasis. Front Endocrinol (Lausanne). 2014; 5:206.

122. Ortiz-Meoz RF, Jiang J, Lazarus MB, Orman M, Janetzko J, Fan C, Duveau DY, Tan ZW, Thomas CJ, Walker S. A small molecule that inhibits OGT activity in cells. ACS Chem Biol. 2015; 10:1392-97.

123. Gloster TM, Zandberg WF, Heinonen JE, Shen DL, Deng L, Vocadlo DJ. Hijacking a biosynthetic pathway yields a glycosyltransferase inhibitor within cells. Nat Chem Biol. 2011; 7:174-81.

124. Weigert C, Klopfer K, Kausch C, Brodbeck K, Stumvoll M, Häring HU, Schleicher ED. Palmitate-induced activation of the hexosamine pathway in human myotubes: increased expression of glutamine:fructose-6-phosphate aminotransferase. Diabetes. 2003; 52:650-56.

125. Marshall S, Nadeau O, Yamasaki K. Dynamic actions of glucose and glucosamine on hexosamine biosynthesis in isolated adipocytes: differential effects on glucosamine 6-phosphate, UDP-N-acetylglucosamine, and ATP levels. J Biol Chem. 2004; 279:35313-19.

126. Banerjee PS, Hart GW, Cho JW. Chemical approaches to study O-GlcNAcylation. Chem Soc Rev. 2013; 42:4345-57.

127. Haltiwanger RS, Blomberg MA, Hart GW. Glycosylation of nuclear and cytoplasmic proteins. Purification and characterization of a uridine diphospho-N-acetylglucosamine:polypeptide beta-Nacetylglucosaminyltransferase. J Biol Chem. 1992; 267:9005-13.

128. Kreppel LK, Hart GW. Regulation of a cytosolic and nuclear O-GlcNAc transferase. Role of the tetratricopeptide repeats. J Biol Chem. 1999; 274:32015-22.

129. Lubas WA, Hanover JA. Functional expression of O-linked GlcNAc transferase. Domain structure and substrate specificity. J Biol Chem. 2000; 275:10983-88.

130. Shen DL, Gloster TM, Yuzwa SA, Vocadlo DJ. Insights into O-linked N-acetylglucosamine ([0-9]O-GlcNAc) processing and dynamics through kinetic analysis of O-GlcNAc transferase and O-GlcNAcase activity on protein substrates. J Biol Chem. 2012; 287:15395-408.

131. Xu J, Wang S, Viollet B, Zou MH. Regulation of the proteasome by AMPK in endothelial cells: the role of O-GlcNAc transferase (OGT). PLoS One. 2012; 7:e36717.

132. Bullen JW, Balsbaugh JL, Chanda D, Shabanowitz J, Hunt DF, Neumann D, Hart GW. Cross-talk between two essential nutrient-sensitive enzymes: O-GlcNAc transferase (OGT) and AMP-activated protein kinase (AMPK). J Biol Chem. 2014; 289:10592-606.

133. Xu Q, Yang C, Du Y, Chen Y, Liu H, Deng M, Zhang H, Zhang L, Liu T, Liu Q, Wang L, Lou Z, Pei H. AMPK regulates histone H2B O-GlcNAcylation. Nucleic Acids Res. 2014; 42:5594-604.

134. Okuyama R, Marshall S. UDP-N-acetylglucosaminyl transferase (OGT) in brain tissue: temperature sensitivity and subcellular distribution of cytosolic and nuclear enzyme. J Neurochem. 2003; 86:1271-80.

135. Marshall S, Duong T, Orbus RJ, Rumberger JM, Okuyama R. Measurement of UDP-N-acetylglucosaminyl transferase (OGT) in brain cytosol and characterization of anti-OGT antibodies. Anal Biochem. 2003; 314:169-79.

136. Marshall S, Okuyama R. Differential effects of vanadate on UDP-N-acetylglucosaminyl transferase activity derived from cytosol and nucleosol. Biochem Biophys Res Commun. 2004; 318:911-15.

137. DeBerardinis RJ. Is cancer a disease of abnormal cellular metabolism? New angles on an old idea. Genet Med. 2008; 10:767-77. 
138. Slawson C, Copeland RJ, Hart GW. O-GlcNAc signaling: a metabolic link between diabetes and cancer? Trends Biochem Sci. 2010; 35:547-55.

139. Deberardinis RJ, Sayed N, Ditsworth D, Thompson CB. Brick by brick: metabolism and tumor cell growth. Curr Opin Genet Dev. 2008; 18:54-61.

140. Iyer SP, Hart GW. Roles of the tetratricopeptide repeat domain in O-GlcNAc transferase targeting and protein substrate specificity. J Biol Chem. 2003; 278:24608-16.

141. Iyer SP, Akimoto Y, Hart GW. Identification and cloning of a novel family of coiled-coil domain proteins that interact with O-GlcNAc transferase. J Biol Chem. 2003; 278:5399-409.

142. Yang X, Zhang F, Kudlow JE. Recruitment of O-GlcNAc transferase to promoters by corepressor $\mathrm{mSin} 3 \mathrm{~A}$ : coupling protein O-GlcNAcylation to transcriptional repression. Cell. 2002; 110:69-80.

143. Hwang SY, Hwang JS, Kim SY, Han IO. O-GlcNAc transferase inhibits LPS-mediated expression of inducible nitric oxide synthase through an increased interaction with mSin3A in RAW264.7 cells. Am J Physiol Cell Physiol. 2013; 305:C601-08.

144. Housley MP, Rodgers JT, Udeshi ND, Kelly TJ, Shabanowitz J, Hunt DF, Puigserver P, Hart GW. O-GlcNAc regulates FoxO activation in response to glucose. J Biol Chem. 2008; 283:16283-92.

145. Housley MP, Udeshi ND, Rodgers JT, Shabanowitz J, Puigserver P, Hunt DF, Hart GW. A PGC-1alpha-O-GlcNAc transferase complex regulates FoxO transcription factor activity in response to glucose. J Biol Chem. 2009; 284:5148-57.

146. Cheung WD, Sakabe K, Housley MP, Dias WB, Hart GW. O-linked beta-N-acetylglucosaminyltransferase substrate specificity is regulated by myosin phosphatase targeting and other interacting proteins. J Biol Chem. 2008; 283:33935-41.

147. Chen Q, Chen Y, Bian C, Fujiki R, Yu X. TET2 promotes histone O-GlcNAcylation during gene transcription. Nature. 2013; 493:561-64.

148. Vella P, Scelfo A, Jammula S, Chiacchiera F, Williams K, Cuomo A, Roberto A, Christensen J, Bonaldi T, Helin K, Pasini D. Tet proteins connect the O-linked $\mathrm{N}$-acetylglucosamine transferase Ogt to chromatin in embryonic stem cells. Mol Cell. 2013; 49:645-56.

149. Deplus R, Delatte B, Schwinn MK, Defrance M, Méndez J, Murphy N, Dawson MA, Volkmar M, Putmans P, Calonne E, Shih AH, Levine RL, Bernard O, et al. TET2 and TET3 regulate GlcNAcylation and $\mathrm{H} 3 \mathrm{~K} 4$ methylation through OGT and SET1/COMPASS. EMBO J. 2013; 32:645-55.

150. Ito R, Katsura S, Shimada H, Tsuchiya H, Hada M, Okumura T, Sugawara A, Yokoyama A. TET3-OGT interaction increases the stability and the presence of OGT in chromatin. Genes Cells. 2014; 19:52-65.

151. Whisenhunt TR, Yang X, Bowe DB, Paterson AJ, Van Tine BA, Kudlow JE. Disrupting the enzyme complex regulating O-GlcNAcylation blocks signaling and development. Glycobiology. 2006; 16:551-63.
152. Bindesbøll C, Fan Q, Nørgaard RC, MacPherson L, Ruan HB, Wu J, Pedersen TA, Steffensen KR, Yang X, Matthews J, Mandrup S, Nebb HI, Grønning-Wang LM. Liver X receptor regulates hepatic nuclear O-GlcNAc signaling and carbohydrate responsive element-binding protein activity. $\mathrm{J}$ Lipid Res. 2015; 56:771-85.

153. Fang B, Miller MW. Use of galactosyltransferase to assess the biological function of O-linked $\mathrm{N}$-acetyl-d-glucosamine: a potential role for O-GlcNAc during cell division. Exp Cell Res. 2001; 263:243-53.

154. Slawson C, Shafii S, Amburgey J, Potter R. Characterization of the O-GlcNAc protein modification in Xenopus laevis oocyte during oogenesis and progesterone-stimulated maturation. Biochim Biophys Acta. 2002; 1573:121-29.

155. Dehennaut V, Lefebvre T, Sellier C, Leroy Y, Gross B, Walker S, Cacan R, Michalski JC, Vilain JP, Bodart JF. O-linked $\mathrm{N}$-acetylglucosaminyltransferase inhibition prevents G2/M transition in Xenopus laevis oocytes. J Biol Chem. 2007; 282:12527-36.

156. Slawson C, Lakshmanan T, Knapp S, Hart GW. A mitotic GlcNAcylation/phosphorylation signaling complex alters the posttranslational state of the cytoskeletal protein vimentin. Mol Biol Cell. 2008; 19:4130-40.

157. Burén S, Gomes AL, Teijeiro A, Fawal MA, Yilmaz M, Tummala KS, Perez M, Rodriguez-Justo M, Campos-Olivas R, Megías D, Djouder N. Regulation of OGT by URI in Response to Glucose Confers c-MYC-Dependent Survival Mechanisms. Cancer Cell. 2016; 30:290-307.

158. Vocadlo DJ. O-GlcNAc processing enzymes: catalytic mechanisms, substrate specificity, and enzyme regulation. Curr Opin Chem Biol. 2012; 16:488-97.

159. Kaasik K, Kivimäe S, Allen JJ, Chalkley RJ, Huang Y, Baer K, Kissel H, Burlingame AL, Shokat KM, Ptáček LJ, Fu YH. Glucose sensor O-GlcNAcylation coordinates with phosphorylation to regulate circadian clock. Cell Metab. 2013; 17:291-302.

160. Vosseller K, Sakabe K, Wells L, Hart GW. Diverse regulation of protein function by O-GlcNAc: a nuclear and cytoplasmic carbohydrate post-translational modification. Curr Opin Chem Biol. 2002; 6:851-57.

161. Tai HC, Khidekel N, Ficarro SB, Peters EC, Hsieh-Wilson LC. Parallel identification of O-GlcNAc-modified proteins from cell lysates. J Am Chem Soc. 2004; 126:10500-01.

162. Khidekel N, Ficarro SB, Clark PM, Bryan MC, Swaney DL, Rexach JE, Sun YE, Coon JJ, Peters EC, Hsieh-Wilson LC. Probing the dynamics of O-GlcNAc glycosylation in the brain using quantitative proteomics. Nat Chem Biol. 2007; 3:339-48.

163. Ryu IH, Do SI. Denitrosylation of S-nitrosylated OGT is triggered in LPS-stimulated innate immune response. Biochem Biophys Res Commun. 2011; 408:52-57.

164. Seo HG, Kim HB, Kang MJ, Ryum JH, Yi EC, Cho JW. Identification of the nuclear localisation signal of O-GlcNAc transferase and its nuclear import regulation. Sci Rep. 2016; 6:34614. 
165. Dorfmueller HC, Borodkin VS, Blair DE, Pathak S, Navratilova I, van Aalten DM. Substrate and product analogues as human O-GlcNAc transferase inhibitors. Amino Acids. 2011; 40:781-92.

166. Schimpl M, Zheng X, Borodkin VS, Blair DE, Ferenbach AT, Schüttelkopf AW, Navratilova I, Aristotelous T, Albarbarawi O, Robinson DA, Macnaughtan MA, van Aalten DM. O-GlcNAc transferase invokes nucleotide sugar pyrophosphate participation in catalysis. Nat Chem Biol. 2012; 8:969-74.

167. Donovan K, Alekseev O, Qi X, Cho W, Azizkhan-Clifford J. O-GlcNAc modification of transcription factor $\mathrm{Sp} 1$ mediates hyperglycemia-induced VEGF-A upregulation in retinal cells. Invest Ophthalmol Vis Sci. 2014; 55:7862-73.

168. Konrad RJ, Zhang F, Hale JE, Knierman MD, Becker GW, Kudlow JE. Alloxan is an inhibitor of the enzyme O-linked $\mathrm{N}$-acetylglucosamine transferase. Biochem Biophys Res Commun. 2002; 293:207-12.

169. Liu J, Yu Y, Fan YZ, Chang H, Liu HM, Cui Y, Chen Q, Wang R. Cardiovascular effects of endomorphins in alloxan-induced diabetic rats. Peptides. 2005; 26:607-14.

170. Xu C, Liu G, Liu X, Wang F. O-GlcNAcylation under hypoxic conditions and its effects on the blood-retinal barrier in diabetic retinopathy. Int J Mol Med. 2014; 33:624-32.

171. Elsner M, Tiedge M, Guldbakke B, Munday R, Lenzen S. Importance of the GLUT2 glucose transporter for pancreatic beta cell toxicity of alloxan. Diabetologia. 2002; 45:1542-49.

172. Zhang H, Gao G, Brunk UT. Extracellular reduction of alloxan results in oxygen radical-mediated attack on plasma and lysosomal membranes. APMIS. 1992; 100:317-25.

173. Hennebicq-Reig S, Lesuffleur T, Capon C, De Bolos C, Kim I, Moreau O, Richet C, Hémon B, Recchi MA, Maës E, Aubert JP, Real FX, Zweibaum A, et al. Permanent exposure of mucin-secreting HT-29 cells to benzyl-N-acetyl-alphaD-galactosaminide induces abnormal O-glycosylation of mucins and inhibits constitutive and stimulated MUC5AC secretion. Biochem J. 1998; 334:283-95.

174. James LR, Tang D, Ingram A, Ly H, Thai K, Cai L, Scholey JW. Flux through the hexosamine pathway is a determinant of nuclear factor kappaB- dependent promoter activation. Diabetes. 2002; 51:1146-56.

175. Gross BJ, Kraybill BC, Walker S. Discovery of O-GlcNAc transferase inhibitors. J Am Chem Soc. 2005; 127:14588-89.

176. Filhoulaud G, Guillemain G, Scharfmann R. The hexosamine biosynthesis pathway is essential for pancreatic beta cell development. J Biol Chem. 2009; 284:24583-94.

177. Jeon JH, Suh HN, Kim MO, Ryu JM, Han HJ. Glucosamineinduced OGT activation mediates glucose production through cleaved Notch1 and FoxO1, which coordinately contributed to the regulation of maintenance of self-renewal in mouse embryonic stem cells. Stem Cells Dev. 2014; 23:2067-79.

178. Suh HN, Lee YJ, Kim MO, Ryu JM, Han HJ. Glucosamineinduced Sp1 O-GlcNAcylation ameliorates hypoxiainduced SGLT dysfunction in primary cultured renal proximal tubule cells. J Cell Physiol. 2014; 229:1557-68.

179. Angelova M, Ortiz-Meoz RF, Walker S, Knipe DM. Inhibition of O-Linked N-Acetylglucosamine Transferase Reduces Replication of Herpes Simplex Virus and Human Cytomegalovirus. J Virol. 2015; 89:8474-83.

180. Borodkin VS, Schimpl M, Gundogdu M, Rafie K, Dorfmueller HC, Robinson DA, van Aalten DM. Bisubstrate UDP-peptide conjugates as human O-GlcNAc transferase inhibitors. Biochem J. 2014; 457:497-502.

181. Chou TY, Hart GW, Dang CV. c-Myc is glycosylated at threonine 58, a known phosphorylation site and a mutational hot spot in lymphomas. J Biol Chem. 1995; 270:18961-65. 